\title{
Serotonergic Plasticity in the Dorsal Raphe Nucleus Characterizes Susceptibility and Resilience to Anhedonia
}

\author{
DNandkishore Prakash, Christiana J. Stark, Maria N. Keisler, Lily Luo, Andre Der-Avakian, ${ }^{\star}$ and Davide Dulcis* \\ Department of Psychiatry, University of California San Diego, La Jolla, California 92093
}

Chronic stress induces anhedonia in susceptible but not resilient individuals, a phenomenon observed in humans as well as animal models, but the molecular mechanisms underlying susceptibility and resilience are not well understood. We hypothesized that the serotonergic system, which is implicated in stress, reward, and antidepressant therapy, may play a role. We found that plasticity of the serotonergic system contributes to the differential vulnerability to stress displayed by susceptible and resilient animals. Stress-induced anhedonia was assessed in adult male rats using social defeat and intracranial self-stimulation, while changes in serotonergic phenotype were investigated using immunohistochemistry and in situ hybridization. Susceptible, but not resilient, rats displayed an increased number of neurons expressing the biosynthetic enzyme for serotonin, tryptophan-hydroxylase-2 (TPH2), in the ventral subnucleus of the dorsal raphe nucleus (DRv). Further, a decrease in the number of DRv glutamatergic (VGLUT3 +) neurons was observed in all stressed rats. This neurotransmitter plasticity is activity-dependent, as was revealed by chemogenetic manipulation of the central amygdala, a stress-sensitive nucleus that forms a major input to the DR. Activation of amygdalar corticotropin-releasing hormone $(\mathrm{CRH})+$ neurons abolished the increase in DRv TPH2 + neurons and ameliorated stress-induced anhedonia in susceptible rats. These findings show that activation of amygdalar CRH + neurons induces resilience, and suppresses the gain of serotonergic phenotype in the DRv that is characteristic of susceptible rats. This molecular signature of vulnerability to stress-induced anhedonia and the active nature of resilience could be targeted to develop new treatments for stress-related disorders like depression.

Key words: anhedonia; central amygdala; dorsal raphe; neurotransmitter plasticity; serotonin; susceptibility and resilience

Significance Statement

Depression and other mental disorders can be induced by chronic or traumatic stressors. However, some individuals are resilient and do not develop depression in response to chronic stress. A complete picture of the molecular differences between susceptible and resilient individuals is necessary to understand how plasticity of limbic circuits is associated with the pathophysiology of stress-related disorders. Using a rodent model, our study identifies a novel molecular marker of susceptibility to stress-induced anhedonia, a core symptom of depression, and a means to modulate it. These findings will guide further investigation into cellular and circuit mechanisms of resilience, and the development of new treatments for depression.

\section{Introduction}

Anhedonia, defined by the Diagnostic and Statistical Manual of Mental Disorders (DSM-5) as the lack of pleasure or interest

Received July 26, 2019; revised Oct. 4, 2019; accepted Nov. 6, 2019

Author contributions: N.P., A.D.-A., and D.D. designed research; N.P., C.J.S., M.N.K., and L.L. performed research; N.P. analyzed data; N.P., A.D.-A., and D.D. wrote the paper.

This work was supported by the Kavli Institute for Brain and Mind (Grant 2012-008 to D.D.), the Tobacco-Related Disease Research Program (Grant 27IR-0020 to D.D.), the National Institute of Drug Addiction (Grant R21-DA047455 to D.D.), the National Institute of Mental Health (Grant R01 MH106865 to A.D.-A.), and the National Institute on Alcohol Abuse and Alcoholism (Grant R01 AA026560 to A.D.-A.). We thank Dr. Robert 0. Messing, University of Texas, Austin, for kindly gifting us breeding pairs for the Crh-cre transgenic rat line; Dr. Christina M. Gremel, Dr. Thomas S. Hnasko, and Dr. Samuel Barnes for their critical feedback on the research; and Dr. Byung Kook Lim for his valuable feedback and the use of his slide-scanning microscope.

The authors declare no competing financial interests.

*A.D.-A. and D.D. contributed equally as co-senior authors.

Correspondence should be addressed to Davide Dulcis at ddulcis@ucsd.edu.
(American Psychiatric Association, 2013), is a debilitating symptom of several psychiatric disorders, including major depressive disorder (MDD). It reflects impaired brain reward function and has been modeled in rodents and primates using multiple behavioral paradigms that capture different aspects of reward processing (Treadway and Zald, 2011; Der-Avakian et al., 2015; Alexander et al., 2019).

The intracranial self-stimulation (ICSS) procedure provides a direct and quantitative measure of anhedonia in rodents (Olds and Milner, 1954; Carlezon and Chartoff, 2007; Negus and Miller, 2014), which can be induced by stressors like social defeat (Martinez et al., 1998a; Rygula et al., 2005; Der-Avakian et al., 2014; Riga et al., 2015). However, not all stressed rodents develop 
anhedonia (Krishnan et al., 2007; Der-Avakian et al., 2014), a phenomenon mimicking resilience to stressful or traumatic experiences in humans (Zisook et al., 1997; Bonanno et al., 2002). The mechanisms determining susceptibility or resilience to stress-induced anhedonia have important implications for understanding and developing treatments for disorders like MDD (Russo et al., 2012).

Neurotransmission mediated by serotonin [5-hydroxytryptamine (5-HT)] is involved in the processing of stress (Chaouloff et al., 1999; Hale et al., 2012; Backström and Winberg, 2017), reward (Kranz et al., 2010; Seymour et al., 2012; Liu et al., 2014; Li et al., 2016; Wang et al., 2019) and emotional behaviors (Hariri et al., 2002; Herrmann et al., 2006; Roiser et al., 2007). Its role in the pathophysiology of many neurological (Chugani et al., 1997; Ener et al., 2003) and psychiatric disorders (López-Ibor, 1988; Lucki, 1998; Müller and Homberg, 2015) is well established. Knock-out mice lacking key components of serotonergic machinery show altered stress-related behaviors (Holmes et al., 2003; Lira et al., 2003; Adamec et al., 2006; Gutknecht et al., 2015). Extracellular levels of serotonin (Kawahara et al., 1993; Mokler et al., 2007), expression of serotonin-related molecules (Adell et al., 1988; Zhang et al., 2012; Issler et al., 2014; Donner et al., 2018), serotonergic activity (Grahn et al., 1999; Paul et al., 2011; Grandjean et al., 2019), and innervation (Natarajan et al., 2017) have been shown to change in response to both acute and chronic stress. Such regulation is linked to behavioral changes including anhedonia (Berton et al., 1997; Wood et al., 2013; Lopes et al., 2016; Natarajan et al., 2017) and is altered by treatment with antidepressants and anxiolytics (Benmansour et al., 1999; Abumaria et al., 2007). Accordingly, we investigated serotonergic circuitry for mechanisms that could explain susceptibility and resilience to stress-induced anhedonia.

Serotonin is mainly synthesized in the raphe nuclei (Dahlström and Fuxe, 1964; Steinbusch, 1981; Jacobs and Azmitia, 1992; Hornung, 2003) by the enzyme tryptophan hydroxylase 2 (TPH2; Walther et al., 2003; Zhang et al., 2004). Among the raphe nuclei, the dorsal raphe nucleus (DR) accounts for most serotonergic cell bodies both in rat (Jacobs and Azmitia, 1992) and human brains (Baker et al., 1990, 1991).

Earlier studies have found that the number of serotonergic neurons (Underwood et al., 1999), levels of Tph2 mRNA (BachMizrachi et al., 2008), and TPH2 protein (Boldrini et al., 2005) are elevated in the DR of deceased patients who committed suicide. These results led us to hypothesize that chronic stressinduced plasticity of serotonergic expression may occur in the $\mathrm{DR}$ and play a role in determining susceptibility or resilience to anhedonia. Neurotransmitter plasticity (Demarque and Spitzer, 2010; Dulcis and Spitzer, 2012; Dulcis, 2016) has not been explored previously in the DR or other brain regions in animal models of anhedonia.

Here, we describe a mechanism of neurotransmitter plasticity involving increased number of $\mathrm{TPH} 2+$ neurons in the DR in susceptible rats following chronic stress. We further demonstrate that manipulation of DR activity can rescue the neurotransmitter phenotype and behavior.

\section{Materials and Methods}

Animals. Adult male rats were used for all experiments. All rats were housed in a $12 \mathrm{~h}$ reverse light/dark cycle with ad libitum access to food and water. Wistar rats (Charles River Laboratories) weighing 300-400 g $(\sim 8$ weeks old) were used for Intracranial Self Stimulation (ICSS) electrode implantation surgeries, behavior, and immunohistochemistry, in experiments without chemogenetic manipulation. Crh-cre transgenic male Wistar rats [knock-in rat strain expressing bacterial Cre recombinase under the promoter for corticotropin-releasing hormone $(\mathrm{Crh})]$, generously provided by Dr. Robert O. Messing, University of Texas at Austin, were bred in our vivarium and used for the chemogenetics experiment. Details of development of the Crh-cre rats were described by Pomrenze et al. (2015). For social defeat, male Long-Evans rats (retired breeders; Charles River Laboratories) co-housed with females and litters were used as resident aggressors. All rats were pair-housed except during social defeat. Crh-cre breeding pairs were at least 10 weeks old and either pair-housed or harem-housed ( 2 females with 1 male). Pups were weaned from the dam and genotyped $21 \mathrm{~d}$ after birth. All experiments were performed in accordance with the guidelines of the Association for Assessment and Accreditation for Laboratory Animal Care (AAALAC) and National Research Council's Guide for the Care and Use of Laboratory Animals and approved by the UCSD Institutional Animal Care and Use Committee.

Genotyping. Ear tissue punches ( $2 \mathrm{~mm}$ diameter) were collected from Crh-cre progeny for DNA extraction and genotyping. For DNA extraction, tissue was incubated in $75 \mu \mathrm{l}$ alkaline lysis buffer $(25 \mathrm{~mm} \mathrm{NaOH}, 0.2$ mM EDTA, $\mathrm{pH} 12.0$ ) at $95^{\circ} \mathrm{C}$ for $1 \mathrm{~h}$ followed by addition of equal volume of neutralization buffer ( $40 \mathrm{~mm}$ Tris- $\mathrm{HCl}, \mathrm{pH} 5.0)$ and short-term storage at $4^{\circ} \mathrm{C}$. The mixture was used as a DNA source for PCR-based genotyping. PCR protocol: $0.5 \mu \mathrm{l}$ of DNA, $0.5 \mu \mathrm{l}$ each of forward and reverse primers, $5 \mu$ l of KAPA2G Fast HotStart ReadyMix (KK5603, KAPA Biosystems) and $3.5 \mu \mathrm{l}$ of sterile water were mixed in a $10 \mu \mathrm{l}$ reaction. Forward and reverse primers for cre, 5'-GCATTACCGGTCGATGC AACGAGTGATGAG-3' and 5' -GAGTGAACGAACCTGGTCGAAATC AGTGCG-3', respectively (Washington University Mouse Genetic Core; mgc.wustl.edu), were used. Cycling parameters were $95^{\circ} \mathrm{C}$ for $3 \mathrm{~min} ; 30$ cycles of $95^{\circ} \mathrm{C}$ for $15 \mathrm{~s}, 60^{\circ} \mathrm{C}$ for $60 \mathrm{~s}, 72^{\circ} \mathrm{C}$ for $40 \mathrm{~s} ; 72^{\circ} \mathrm{C}$ for $2 \mathrm{~min}$ in a T100 Thermal Cycler (Bio-Rad) followed by long-term storage at $-20^{\circ} \mathrm{C}$. PCR product was analyzed by horizontal agarose gel electrophoresis and presence of $550 \mathrm{bp}$ band was determined to identify cre-positive progeny.

Surgery. For ICSS electrode implantations, rats were anesthetized with a $5 \%$ isoflurane/oxygen vapor mixture and attached to a stereotaxic frame (Kopf Instruments) where continuous flow of 2\% isoflurane/oxygen was administered throughout the procedure. The incisor bar was set at $5.0 \mathrm{~mm}$ above the interaural line. Bipolar insulated stainless-steel electrodes (11 mm length; model MS303/2, Plastics One) were unilaterally (counterbalanced) implanted in the posterior lateral hypothalamus (AP: $-0.5 \mathrm{~mm}, \mathrm{ML}: \pm 1.7 \mathrm{~mm}$ from bregma, and DV: $-8.3 \mathrm{~mm}$ from dura). The electrode was secured using dental acrylic and $4-6$ stainless steel jeweler's screws. The exposed electrode pedestal was shielded using a metal screw cap to prevent damage.

For chemogenetics, bilateral viral injections $(1.0 \mu \mathrm{l} / \mathrm{side})$ into the lateral subnucleus of the central amygdala (AP: $-2.3 \mathrm{~mm}, \mathrm{ML}: \pm 4.7 \mathrm{~mm}$ from bregma, and DV: $-6.9 \mathrm{~mm}$ from dura, head parallel to horizontal) were performed using a 30G metal cannula (Plastics One) connected to a Hamilton syringe pump (10 $\mu \mathrm{l}$ syringe) at a rate of $0.1 \mu \mathrm{l} / \mathrm{min}$ before electrode implantation during the same surgical procedure. Rats were injected with either the control virus (AAVDJ-Syn1-DIO-eGFP, 1.78E+13 GC/ml; Salk Institute; ) or the excitatory DREADD receptor-encoding virus (AAV5hSyn-DIO-hM3Dq-mCherry, 6.50E+12 GC/ml; Addgene).

The AAV-DJ vector used for the control virus is a recombinant version of 8 AAV serotypes including AAV5 (Grimm et al., 2008) and is reported to have a higher transduction efficiency than natural AAV serotypes. Both constructs used in this study have Cre-dependent expression under promoters (Syn1 and hSyn), which are murine and human homologs, respectively, of the promoter for the same gene, synapsin I. Further, the fluorophore (eGFP or mCherry) does not contribute to viral transduction, expression or the subsequent activation of infected neurons. This results in the two viruses infecting a similar population of Cre-expressing neurons in the central amygdala, making the AAVDJ-Syn1-DIO-eGFP virus an effective control for expression and activation of the excitatory DREADD receptor-encoding virus.

Viral incubation occurred for at least 8 weeks during the postsurgical recovery, ICSS training, baseline testing, and saline habituation periods. Postsurgical treatment with topical antibiotic cream and $20 \mathrm{mg} / \mathrm{kg}$ (intramuscular) of enrofloxacin was provided to prevent infection. 
Table 1. Antibodies

\begin{tabular}{|c|c|c|}
\hline Antibody & Dilution & Catalog no. (manufacturer) \\
\hline Mouse anti-cFos (monoclonal) & $1: 1000$ & sc-166940 (Santacruz Biotech) \\
\hline Guinea pig anti-NeuN (polyclonal) & $1: 2000$ & ABN90 (Millipore Sigma) \\
\hline Sheep anti-TH (polyclonal) & 1:1000 & AB1542 (Millipore Sigma) \\
\hline Rabbit anti-TPH2 (polyclonal) & $1: 500$ & PA1-778 (ThermoFisher Scientific) \\
\hline Guinea pig anti-VGLUT3 (polyclonal) & $1: 100$ & AB5421-I (Millipore Sigma) \\
\hline Sheep anti-bNOS (polyclonal) & $1: 500$ & AB1529 (Millipore Sigma) \\
\hline Donkey anti-sheep AlexaFluor 647 (secondary) & $1: 500$ & A21448 (Invitrogen) \\
\hline Donkey anti-sheep AlexaFluor 488 (secondary) & $1: 500$ & A11015 (Invitrogen) \\
\hline Donkey anti-guinea pig AlexaFluor 488 (secondary) & $1: 500$ & $706-545-148$ (Jackson ImmunoResearch) \\
\hline Donkey anti-rabbit AlexaFluor 555 (secondary) & $1: 500$ & A31572 (Invitrogen), SAB4600177 (Sigma-Aldrich) \\
\hline Horse anti-rabbit biotinylated (secondary) & $1: 300$ & BA-1100 (Vector Laboratories) \\
\hline Donkey anti-mouse AlexaFluor 647 (secondary) & $1: 500$ & A31571 (Invitrogen) \\
\hline
\end{tabular}

Primary and secondary antibodies used in this study listed with details of host and target species, type (polyclonal, monoclonal, or secondary), working dilution, and product supplier.

ICSS apparatus, training, testing, and analysis. The ICSS procedure, including apparatus, training, and testing, was performed as previously described (Der-Avakian and Markou, 2010). Briefly, rats were trained to seek reinforcement of direct current stimulation of the posterior lateral hypothalamus by turning a wheel manipulandum in the testing chamber. A noncontingent stimulus ( $100 \mathrm{~Hz}$ electrical pulse train) of current intensity varying from 50 to $300 \mu \mathrm{A}$ was delivered to the rat by means of a computer-controlled constant current stimulator (Stimtek Model 1200c, San Diego Instruments). Rats were trained to turn a wheel in response to the noncontingent stimulus to receive a second (contingent) stimulus with identical parameters. Current intensities were systematically varied across trials, separated by intertrial intervals without stimulation. Using this discrete-trial current-intensity procedure, the minimum current intensity required to elicit a response from the rat was measured and defined as the reward threshold. Reward thresholds were measured every day, at the same time, in trained rats. Thresholds were monitored for 3-6 weeks until they were stable (i.e., $<10 \%$ variation over 5 consecutive days). The baseline threshold for each rat was calculated as the average of its daily thresholds for $3 \mathrm{~d}$ before the beginning of testing. Rats with stable thresholds were divided into control and stress groups. For the chemogenetics experiment, litter effects were avoided by distributing rats from different litters across groups. Controls were tested in the ICSS procedure daily and stressed rats were tested daily within 15 min of a social defeat encounter. Elevations in thresholds indicated that a greater current intensity was required to generate positive reinforcement, reflecting an anhedonic state. A rat was classified as susceptible to anhedonia if its average threshold during Days 19-21 of social defeat was $>3$ SD from the pre-defeat baseline thresholds of the cohort (calculated by averaging baseline thresholds across all stressed rats). Daily reward thresholds were plotted as percentage changes from baseline averaged across rats in each group.

Chronic social defeat. A resident-intruder procedure was used as previously described (Der-Avakian et al., 2014). Long-Evans males (residents), prescreened for aggression and dominance, were housed in a large cage $(61 \times 43 \times 20 \mathrm{~cm})$ with females and progeny. During social defeat $(21 \mathrm{~d})$, the experimental male Wistar (intruder) was co-housed with the resident but physically separated by an acrylic partition that allowed for exchange of visual, auditory, and olfactory information between the intruder and the residents. For $3 \mathrm{~min}$ each day, the female resident and pups were removed from the cage, and the partition was lifted to allow a direct physical interaction between the males. Social defeat was defined as a supine submissive posture of the intruder for 3 consecutive seconds with the resident pinning the intruder down. After a social defeat encounter or $3 \mathrm{~min}$ (whichever occurred first), the intruder was removed and its reward threshold was measured. At the end of each day of testing, the intruder was paired with a different resident for the next $24 \mathrm{~h}$ period. During the $21 \mathrm{~d}$ defeat period, non-stressed controls continued to be pair-housed as during the training and baselining process, and were undisturbed except for daily handling during ICSS testing. This ensured that they served as a control group for all types of stress potentially experienced during the process of social defeat, including physical and sensory stress, as well as social and housing instability associated with the social defeat procedure.

Drug treatment. Clozapine $(0.1 \mathrm{mg} / \mathrm{kg}$; MP Biomedicals $)$ was dissolved in $0.1 \%$ dimethyl sulfoxide (DMSO) in sterile saline and administered intraperitoneally once daily, 30 min before ICSS testing during the $21 \mathrm{~d}$ social defeat procedure. For habituation to intraperitoneal injections, rats across all experimental groups were administered $0.1 \mathrm{ml}$ of $0.1 \%$ DMSO in saline (equal volume and route of administration as for subsequent clozapine injections), $30 \mathrm{~min}$ before ICSS testing daily, for 7-14 d before the start of social defeat until their ICSS baseline thresholds stabilized.

Tissue collection and processing. In all experiments, on day $21,6 \mathrm{~h}$ after social defeat $/$ ICSS testing, rats were administered $0.2-0.3 \mathrm{~g} / \mathrm{kg}$ Fatal-Plus C IIN (pentobarbital sodium, i.p.). After complete loss of reflexes, rats were transcardially perfused with PBS, $\mathrm{pH} 7.5$, until perfusate was colorless, followed by perfusion with equal volume of ice-cold $4 \%$ paraformaldehyde (PFA), pH 7.5, dissolved in PBS. Rats were then decapitated and whole brains were extracted and postfixed in fresh $4 \% \mathrm{PFA}$ for $24 \mathrm{~h}$ at $4^{\circ} \mathrm{C}$ followed by incubation in $30 \%$ sucrose at $4^{\circ} \mathrm{C}$ for $48 \mathrm{~h}$ or until brains were completely submerged. Thirty $\mu \mathrm{m}$ coronal sections of ventral tegmental area (VTA), DR, and $50 \mu \mathrm{m}$ sections of the hypothalamus and amygdala were collected using a microtome (Leica) in a cryoprotectant solution (30\% v/v glycerol, $30 \% \mathrm{v} / \mathrm{v}$ ethylene glycol in PBS, pH 7.4) for long-term storage at $-20^{\circ} \mathrm{C}$ to $-40^{\circ} \mathrm{C}$. For each brain region, every fourth section was collected in the same well as a set of tissue for a given staining procedure.

Immunohistochemistry and in situ hybridization. Antibody details and concentrations are provided in Table 1. All washes and incubations were performed with gentle shaking. Antibodies were diluted in blocking solution (5\% normal horse serum, $0.3 \%$ Triton X-100 in PBS). For immunofluorescence, sections were washed $3 \times$ for $5 \mathrm{~min}$ in PBS, incubated in blocking solution for $30 \mathrm{~min}$ to $1 \mathrm{~h}$, incubated in primary antibody solution overnight at $4^{\circ} \mathrm{C}$, washed $3 \times$ for $10 \mathrm{~min}$ in PBS, incubated in secondary antibody solution for $1 \mathrm{~h}$ at room temperature, washed $3 \times$ for 10 min in PBS, mounted on a positively charged glass slide (Fisherbrand Superfrost Plus, Fisher Scientific) in $0.2 \%$ gelatin in PBS, coverslipped with mounting medium (Fluoromount-G, SouthernBiotech) and sealed with nail polish.

For colorimetric DAB-based immunohistochemistry, brain sections were processed in the following steps: $3 \times 5 \mathrm{~min}$ PBS washes, incubation in $3 \%$ hydrogen peroxide in PBS for $15 \mathrm{~min}$, blocking solution for 30 min, primary antibody overnight at $4^{\circ} \mathrm{C}, 3 \times$ for $10 \mathrm{~min}$ PBS washes, secondary antibody incubation at room temperature for $1 \mathrm{~h}, 3 \times 10 \mathrm{~min}$ PBS washes, incubation in fresh ABC solution (1:1 mixture of Reagents $\mathrm{A}$ and $\mathrm{B}$, each diluted $1: 100$ in $2 \% \mathrm{NaCl} / 0.3 \%$ Triton X-100/PBS; VECTASTAIN HRP Kit, Vector Laboratories) for $1 \mathrm{~h}, 3 \times 10 \mathrm{~min}$ PBS washes, incubation for 3-5 min in 3,3' -diaminobenzidine (DAB; Acros Organics) staining solution (0.025\% w/v DAB, $0.01 \%$ v/v hydrogen peroxide in PBS), $3 \times 10$ min PBS washes, mounting in $0.2 \%$ gelatin in PBS, drying, and coverslipping in Cytoseal 60 (ThermoFisher Scientific) and sealing with nail polish. 
RNAscope v 2.0 (ACD Bio) in situ hybridization in combination with immunofluorescence was performed as per manufacturer's instructions for Tph2 (Part ID 316411), Vglut3 (Part ID 476711-C2), and Pet1 (Fev; Part 487771-C3) mRNA transcripts.

Image acquisition and processing. For fluorescence staining, multichannel confocal $z$-stacks of each tissue section were acquired with $2.5 \mu \mathrm{m}$ distance between optical sections using a Leica SPE confocal microscope $(10 \times$ or $20 \times$ dry objective). Objective resolution and acquisition settings (laser power, gain, pinhole aperture, and signal averaging) were applied uniformly across sections within a given experiment. Maximum intensity $z$-projections were made using Fiji (Schindelin et al., 2012) image analysis software. Linear brightness and contrast adjustments were applied uniformly across all pixels for each image. Images in TIFF format were used for quantification. Mean filter (Fiji) or box blur (Adobe Photoshop CS4) with 2-pixel radius was applied to representative images in figures.

For DAB-stained sections, $20 \times$ bright-field images were acquired using an Olympus Virtual Slide Microscope (VS120) and stored in TIFF format for quantification.

Quantification of cell number. For quantification of cell numbers for each marker, fluorescence or bright-field images (processed as described above) were organized according to their rostrocaudal position and specific sections were chosen by visual inspection for quantification and analysis using the Rat Brain Atlas (Paxinos and Watson, 2014) as a reference. For quantification of TPH2, cFos, NeuN, vesicular glutamate transporter isoform 3 (VGLUT3), neuronal nitric oxide synthase (nNOS) immunofluorescence, and Tph2, Vglut3, and Pet1 mRNA in the midrostrocaudal DR, sections at rostrocaudal positions $-7.76,-7.88$, and $-8.00 \mathrm{~mm}$ from bregma were selected and subdivisions were demarcated based on TPH2 staining pattern with reference to Abrams et al. (2004), Kelly et al. (2011), and Paxinos and Watson (2014). For quantification of TPH2 using DAB staining, sections at rostrocaudal positions $-7.64,-7.76,-7.88,-8.00,-8.12,-8.24$, and $-8.36 \mathrm{~mm}$ from bregma were chosen. Only cells that were in focus, with clearly discernible cellular appearance (size, shape, and cell boundaries) and with intense colorimetric or fluorescent stain filling at least $50 \%$ of the cell's area (by visual estimation), were considered positive. For quantification of tyrosine hydroxylase (TH) in the VTA, every fourth $30 \mu \mathrm{m}$ section between rostrocaudal positions -5.60 and $-6.20 \mathrm{~mm}$ from bregma was chosen. VTA was demarcated based on TH expression with reference to Paxinos and Watson (2014). Fluorescently stained cell bodies were counted unilaterally in the parabrachial pigmented and paranigral nuclei of the VTA, and doubled before analysis and plotting. For quantification of $\mathrm{TH}$ in the periventricular nucleus of the hypothalamus, every fourth $30 \mu \mathrm{m}$ section between rostrocaudal positions -1.40 and $-2.00 \mathrm{~mm}$ from bregma was chosen. The periventricular nucleus was identified by TH expression with reference to Paxinos and Watson (2014) and cell bodies were counted unilaterally and doubled before analysis and plotting. In all rats with chemogenetic manipulation, validation of DREADD receptor expression was performed by visually examining coronal sections of the central amygdala (lateral subnucleus, bilateral) throughout its rostrocaudal extent, for native mCherry or eGFP fluorescence using an Olympus Virtual Slide Microscope (VS120).

Experimental design and statistical analyses. IBM SPSS Statistics 24 software was used for all statistical testing described below. Reward threshold comparisons for non-chemogenetic experiments were made using a mixed ANOVA (with Greenhouse-Geisser correction for sphericity violation as $\varepsilon<0.75$ ) after testing for normality (Shapiro-Wilk's test) and homogeneity of variance (Levene's test). Day was included as a within-subjects factor and Stress (control, susceptible, and resilient) was the between-subjects factor. Significant main and interaction effects were followed with Bonferroni post hoc tests. For cell quantification comparisons in non-chemogenetics experiments, a one-way ANOVA was used (control, susceptible, and resilient groups) after ensuring normality and homoscedasticity of data (Shapiro-Wilk's test and Levene's test, respectively) and Tukey's HSD post hoc tests were performed if applicable. Data that did not satisfy criteria for an ANOVA (not normally distributed) were analyzed using Kruskal-Wallis $H$ tests. Post hoc pairwise betweengroups comparisons using Mann-Whitney $U$ tests with Dunn-Bonfer- roni correction were performed. Data analyzed using nonparametric tests were plotted as median with interquartile range. All data analyzed using parametric tests were plotted as mean with SEM.

For the chemogenetics experiment, rats either expressed the GFP or hM3Dq virus and were split into control and defeat groups after their ICSS baseline thresholds stabilized. All rats were administered $0.1 \%$ DMSO in saline (vehicle) during habituation and clozapine during the $21 \mathrm{~d}$ social defeat period. GFP- and hM3Dq virus expressing non-stressed controls were pooled after ensuring that there was no statistical difference between the groups. Effects of vehicle were tested using one-way repeated-measures ANOVA (Day as within-subjects factor) that included all rats. Reward thresholds were compared using a mixed ANOVA with Day (for analysis of effects of vehicle and clozapine on control groups) or Period (acute: average of Days 1-3 or chronic: average of Days 19-21, for analysis of effect of clozapine on stressed groups) as the within-subjects factor and Group (Control, GFP susceptible, GFP resilient, hM3Dq susceptible, and hM3Dq resilient) as the between-subjects factor. Significant main and interaction effects were followed with Bonferroni post hoc tests. Cell count comparisons between the same five groups were conducted using an ANOVA with Tukey's HSD for post hoc comparisons. The coefficient of correlation between TPH $2+$ counts and reward thresholds was calculated using bivariate Pearson correlation test.

Alpha level was set to 0.05 for all analyses. Appropriate sample sizes for each experiment were determined with standard Cohen's $d$ power analysis with target effect size set to 0.8 and $\alpha$ level to 0.05 . Outliers within any group, determined using the median absolute deviation method (Iglewicz and Hoaglin, 1993) were excluded from statistical analyses. Microsoft Excel and GraphPad Prism 8.0.2 were used for generating plots.

\section{Results}

\section{Susceptible rats show elevated ICSS thresholds after chronic social defeat}

Monitoring ICSS thresholds over $21 \mathrm{~d}$ of social defeat revealed that a subset of rats was susceptible to stress-induced anhedonia, whereas others were resilient (Fig. 1A). Stressed rats whose thresholds at the end of the $21 \mathrm{~d}$ period, were $>3$ SD from baseline, were classified as "susceptible" and others as "resilient". Independently, a $k$ means cluster analysis of thresholds at the end of social defeat (averaged over Days 19-21), split the cohort of stressed rats into identical groups, with susceptible rats forming a separate cluster from resilient rats and unstressed controls (Fig. $1 B$, right). The same cluster separation was not present at the beginning of social defeat (averaged over Days 1-3; Fig. 1B, left), indicating that susceptible/resilient phenotypes were not predictable early during social defeat, in response to acute exposure, but rather developed over time due to chronic stress. There were also no differences in baseline thresholds across groups (Fig. 1C) as determined by a Kruskal-Wallis $H$ test $\left(\chi_{(2)}^{2}=1.233, p=0.540\right)$, indicating that baseline thresholds do not predict ICSS responses to subsequent social defeat. A two-way mixed ANOVA using Greenhouse-Geisser correction $(\varepsilon=0.379)$ revealed a main effect of Stress $\left(F_{(2,25)}=15.998, p=3.40 \mathrm{E}-5\right.$; Fig. $\left.1 A\right)$ but no significant interaction between Stress and Day $\left(F_{(15.177,189.717)}=\right.$ 1.504, $p=0.106)$. However, based on previous evidence that susceptible/resilient phenotypes develop over time (Der-Avakian et al., 2014), which was supported by our observations (Fig. $1 A, B)$, we hypothesized that the behavioral difference between susceptible and resilient rats arises at an intermediate time point during the $21 \mathrm{~d}$ social defeat paradigm. Accordingly, we performed post hoc pairwise comparisons with Bonferroni correction, which revealed that susceptible rats had significantly elevated thresholds $(p<0.05)$ relative to controls on Days $2-10$ and relative to both resilient and control rats from Day 11 onward (Fig. 1A), whereas resilient rats did not differ significantly from controls. Although controls gained weight over time, all stressed 
A

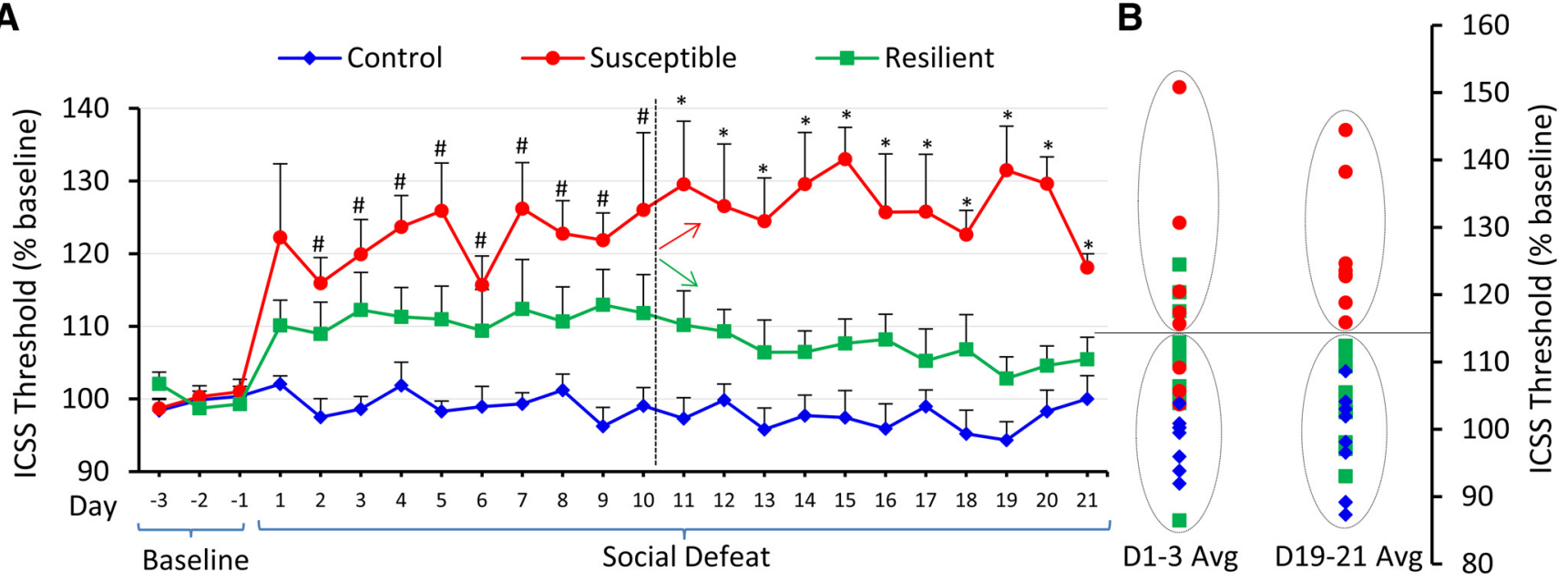

C

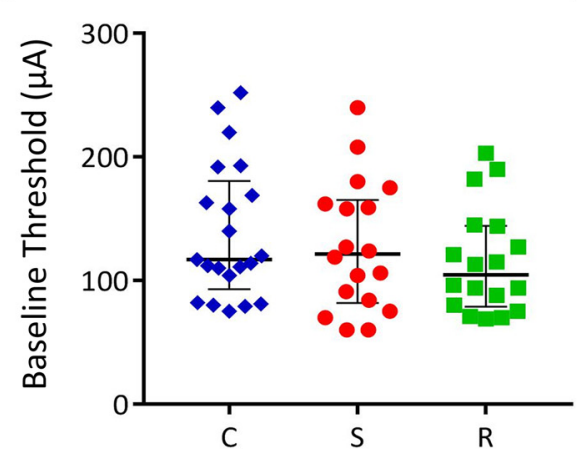

D

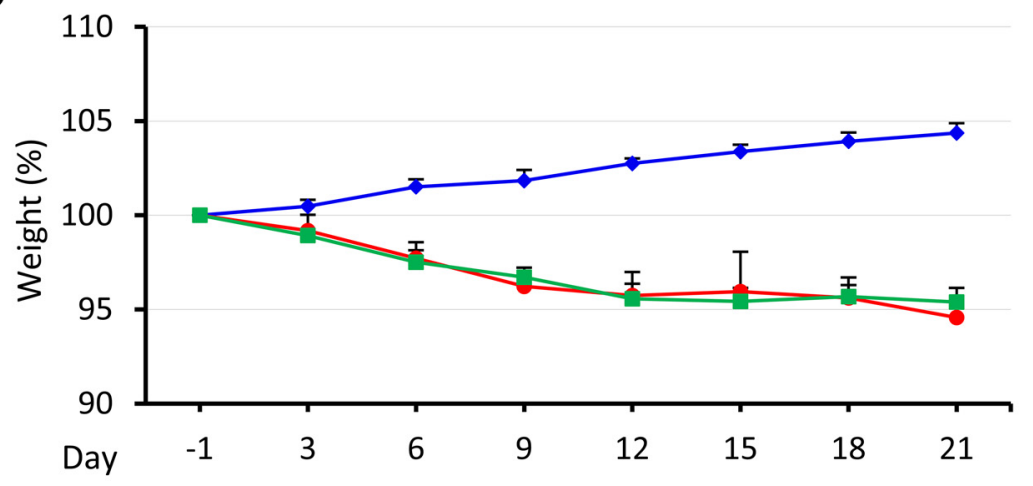

$\mathbf{F}$

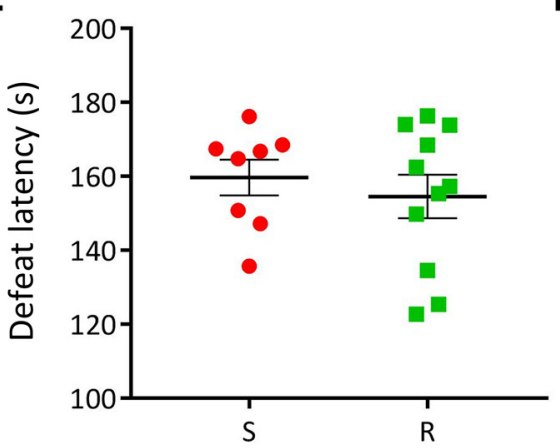

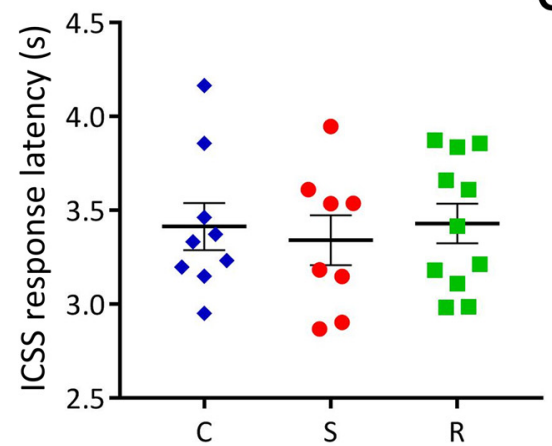

G

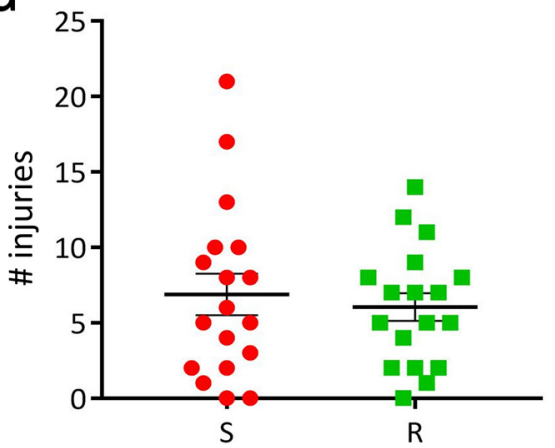

Figure 1. Susceptible rats show elevated ICSS thresholds during stress. $A$, Daily ICSS thresholds (mean across animals + SEM) plotted as percentage of baseline for $3 \mathrm{~d}$ before defeat and for each day of $21 \mathrm{~d}$ social defeat. Control rats $(n=9)$ represented by blue diamonds, susceptible rats $(n=8)$ by red circles, and resilient rats $(n=11)$ by green squares. Significant $(p<0.05)$ post hoc pairwise comparisons for each day shown above error bars. \# indicates a significant difference between susceptible and control groups but not between other pairs. * indicates a significant difference between susceptible and control as well as susceptible and resilient groups. Dashed vertical line after Day 10 indicates the day from which susceptible (red arrow) and resilient (green arrow) groups differ significantly. $B, A$ k means cluster analysis of Days $1-3$ (left) and Days 19-21 (right). $C$, Absolute baseline ICSS current intensity thresholds (in $\mu$ A) for each experimental group (C, control; $S$, susceptible; $R$, resilient). Values are median and interquartile range. $\boldsymbol{D}$, Rat body weight (mean $+\mathrm{SEM}$ ) in grams, measured every $3 \mathrm{~d}$ over $21 \mathrm{~d}$ period and plotted as percentage change relative to baseline (Day -1) for each group. $\boldsymbol{E}$, Latency to supine submissive posture during social defeat, in seconds, plotted for stressed groups as mean \pm SEM. $\boldsymbol{F}$, ICSS response latency (mean \pm SEM) in seconds, plotted for each group. $\boldsymbol{G}$, Total number of injuries (mean \pm SEM) suffered by each rat during $21 \mathrm{~d}$ social defeat plotted for stressed groups. $\boldsymbol{B}-\boldsymbol{E}$, Graph symbols as in $\boldsymbol{A}$.

rats showed a slight decrease in weight over the $21 \mathrm{~d}$ stress period, indicating that the metabolic effects of stress were similar across susceptible and resilient rats (Fig. 1D). Latencies to supine submissive posture during social defeat, a quantitative measure of stress exposure, were also similar between susceptible and resilient groups (Fig. $1 E$ ), indicating that resilient rats were not subjected to any less stress than susceptible rats. Rats across groups did not show a difference relative to controls in latency to respond to ICSS stimulation, indicating that social defeat did not differentially affect motor activity between susceptible, resilient, and control rats (Fig. $1 F$ ). Number of injuries during social defeat was also similar across susceptible and resilient rats (Fig. $1 G$ ), indicating that elevated thresholds in susceptible rats were likely not a function of immune responses to injury.

\section{Susceptible rats display an increased number of TPH2+ neurons in the DRv}

Altered numbers of TPH2 + neurons in the DR have been observed in human victims of suicide (Underwood et al., 1999). Therefore, we counted the number of TPH2 + neurons in each of 
A

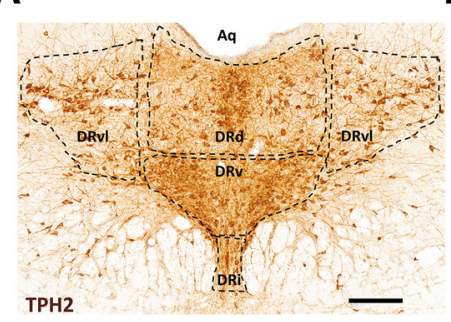

B

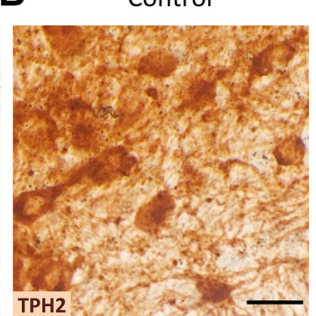

Susceptible

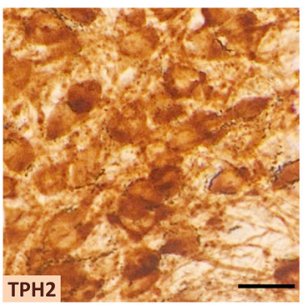

Resilient

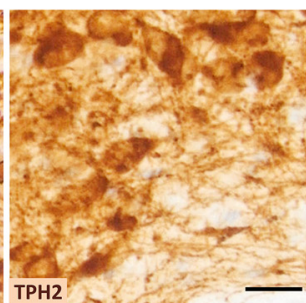

C
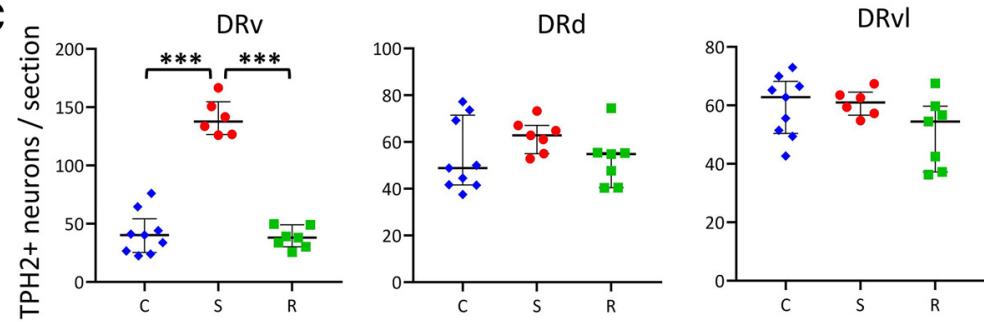

DRi

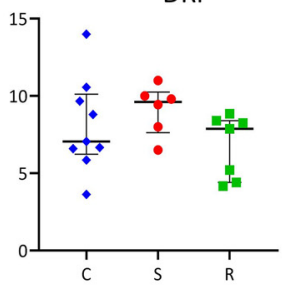

D

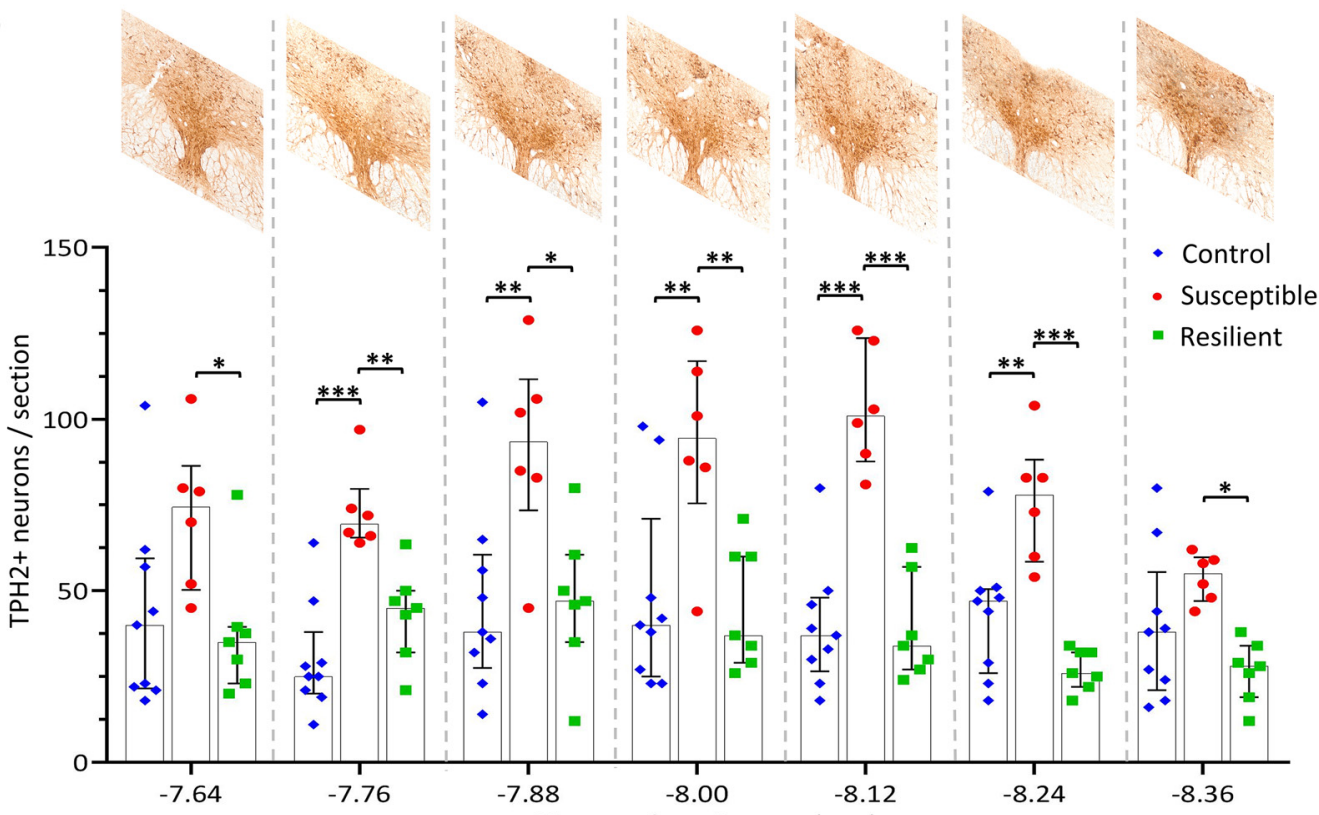

E

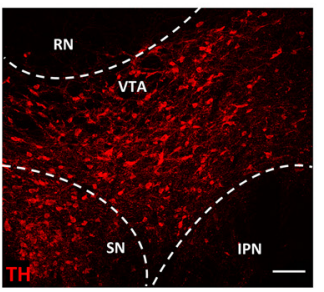

F

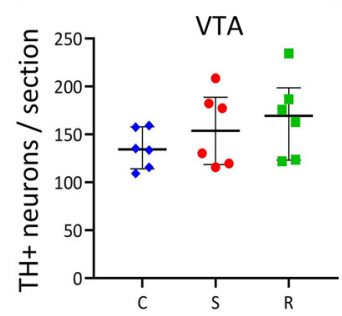

G

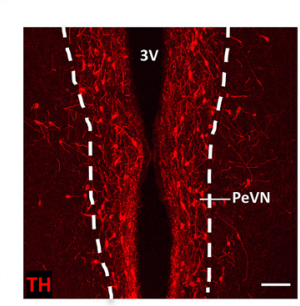

H

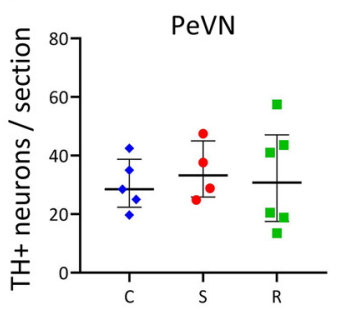

Figure 2. Susceptible rats display more TPH2 + neurons in the ventral subnucleus of the DR. $A$, Representative image of a coronal section through the DR stained for TPH2 (brown) by DAB immunohistochemistry. Various DR subnuclei present at the mid-rostrocaudal level are outlined in black. Aq, Aqueduct of Sylvius. Scale bar, $200 \mu \mathrm{m}$. B, Representative images of DRv sections stained for TPH2 from each experimental group. Scale bars, $25 \mu \mathrm{m}$. C, Number of TPH2 + neurons in each subnucleus of the DR. Counts (per section) were averaged across rats [control (C), blue diamonds, $n=9$; susceptible (S), red circles, $n=6$; resilient (R), green squares, $n=7$ ] and plotted as median with interquartile range. ${ }^{* * *} p<0.001$. D, Quantification of number of TPH2 + neurons in the DRv at $120 \mu \mathrm{m}$ intervals along the rostrocaudal axis within the mid-rostrocaudal DR. Rostrocaudal positions represented on $x$-axis as distance from bregma in $\mathrm{mm}$ and representative images of the DR at each position are shown above. Counts were averaged across rats (graph symbols and sample sizes same as in C) and plotted as median and interquartile range. ${ }^{*} p<0.05,{ }^{* *} p<$ $0.01,{ }^{* * *} p<0.001$. E, Representative image of a coronal section through the VTA, seen unilaterally, outlined in white, stained for TH (red) to mark dopaminergic neurons. IPN, Interpeduncular nucleus; $\mathrm{SN}$, substantia nigra; RN, red nucleus. Scale bar, $100 \mu \mathrm{m}$. $F$, Quantification of number of $\mathrm{TH}+$ neurons per VTA section. Bilateral counts were averaged across six rats per group and plotted as median and interquartile range. Graph symbols as defined in C. G, Representative image of a coronal section through the PeVN, seen bilaterally, stained for TH (red) to mark dopaminergic neurons. 3V, Third ventricle. Scale bar, $100 \mu \mathrm{m}$. $\boldsymbol{H}$, Quantification of number of TH + neurons per PeVN section. Bilateral counts were averaged across rats (control: $n=5$, susceptible: $n=4$, resilient: $n=$ 6) and plotted as median and interquartile range. Graph symbols as defined in $\boldsymbol{C}$. 
the following subnuclei of the mid-rostrocaudal DR: dorsal (DRd), ventral (DRv), ventrolateral "wings" (DRvl), and interfascicular (DRi; Fig. 2A). The number of TPH2+ neurons in the DRv was significantly elevated (Kruskal-Wallis $H$ test, $\chi_{(2)}^{2}=$ $11.528, p=0.003)$ in susceptible rats, relative to control $(p=$ 0.008 , Bonferroni's adjustment) and resilient rats $(p=0.008$, Bonferroni's adjustment; Fig. $2 B, C$ ). The DRd, DRvl, and DRi showed no differences in the average number of TPH $2+$ neurons per section across groups as determined by Kruskal-Wallis $H$ tests (Fig. 2C). Independent Kruskal-Wallis $\mathrm{H}$ tests with post hoc pairwise comparisons using Bonferroni adjustment revealed a significantly increased number of TPH $2+$ neurons $(p<0.05)$ in susceptible rats relative to resilient and control rats at each of the seven rostrocaudal positions examined (Fig. 2D), indicating that stress-induced TPH2 expression was not localized to particular rostrocaudal subregions of the DRv.

Chronic social stressors such as social defeat and maternal separation are known to modulate the number (Chocyk et al., 2011) and firing pattern (Krishnan et al., 2007; Chaudhury et al., 2013) of midbrain dopaminergic neurons (marked by TH). However, the number of $\mathrm{TH}+$ neurons in midbrain regions has not been investigated with respect to susceptibility and resilience to social defeat, although dopaminergic plasticity involving has been observed in the periventricular nucleus $(\mathrm{PeVN})$ of the hypothalamus after photoperiod stress (Dulcis et al., 2013) and the VTA (Romoli et al., 2019) after neonatal exposure to nicotine. Therefore, we asked whether the number of $\mathrm{TH}+$ neurons differed across our experimental groups in these regions. Neither of these regions showed differences across groups as determined by Kruskal-Wallis $H$ tests (Fig. $2 E-H)$, indicating that susceptibility and resilience to anhedonia following chronic social defeat does not involve dopaminergic plasticity in midbrain neurons.

\section{Stressed rats have fewer VGLUT3 + neurons in the DRv}

To identify the source of the newly serotonergic neurons, we first asked whether the increase in $\mathrm{TPH} 2+$ neurons came from an increased number of neurons in the DRv. No significant differences were observed in the total number of mature neurons (marked by NeuN) in the DRv, as measured by a one-way ANOVA (Fig. $3 A, B$ ). We then examined the DRv for changes in neurotransmitter expression within differentiated neurons that normally express other neurotransmitters, and asked whether the extent of their coexpression with TPH 2 changed across experimental groups. Of the various neurotransmitters expressed in the DR (Fu et al., 2010), we chose to examine those previously implicated in stress and reward. Mesolimbic dopamine is a well known mediator of reward (Nestler and Carlezon, 2006) and we investigated whether $\mathrm{DR}$ dopaminergic $(\mathrm{TH}+)$ neurons could display plasticity of TPH2 phenotype. $\mathrm{TH}+$ neurons in the DR did not display any overlap with TPH2 expression and were located very rostrally within the DR, outside the region where increased TPH2 + neurons were observed (Fig. 3C), consistent with previous observations (Fu et al., 2010). Another candidate neurotransmitter in the DR associated with reward and depression is nitric oxide (Gholami et al., 2003; Dhir and Kulkarni, 2007; Zhou et al., 2011). Nitrergic neurons, marked by nNOS, were found to highly coexpress TPH 2 in the DRv (Fig. $3 D, E$ ), with $98.03 \pm 1.44 \%$ of nNOS + neurons coexpressing TPH 2 in non-stressed rats (Fig. $3 E$ ). There were no significant differences in the total number of nNOS+ neurons (Fig. 3I) or nNOS + TPH2 + coexpressing neurons (Fig. 3J) across conditions. VGLUT3-expressing neurons have been shown to coexpress TPH2, project to the VTA, and drive reward (Wang et al., 2019). Accordingly, we immunostained (Fig. $3 F$ ) and quantified the number of DRv glutamatergic neurons, marked by VGLUT3 and found that $86.51 \pm 2.78 \%$ of VGLUT3+ neurons coexpress TPH2 in control brains (Fig. $3 G)$. To test whether VGLUT3 is a "switching partner" for TPH2 as previously shown for TH (Dulcis and Spitzer, 2008; Dulcis et al., 2013), we quantified the number of total VGLUT3+ and VGLUT3 + TPH2 + coexpressing neurons in the DRv. A oneway $\operatorname{ANOVA}\left(F_{(2,14)}=7.001, p=0.008\right)$ revealed a significant decrease in the number of VGLUT3+ neurons in susceptible (Tukey's HSD: $p=0.039$ ) but interestingly, also in resilient (Tukey's HSD: $p=0.007$ ) rats relative to controls (Fig. $3 H, K$ ). The number of VGLUT3 + TPH2 + coexpressing neurons was also decreased in stressed rats (Fig. $3 L$; one-way $\operatorname{ANOVA~} F_{(2,14)}=$ 5.367, $p=0.019$ ) with a significant difference between resilient and control groups (Tukey's HSD: $p=0.023$ ) and a strong trend toward a significant decrease in the susceptible group (Tukey's HSD: $p=0.054)$. This suggests that plasticity of VGLUT3+ phenotype is associated with chronic social defeat stress, and occurs in parallel with plasticity of TPH $2+$ phenotype, which is specific to chronic stress-induced anhedonia.

To test whether the observed changes in TPH2 and VGLUT3 protein arose from changes in the corresponding mRNA, we performed in situ hybridization for Tph2 and Vglut3 mRNA (Fig. $4 A$ ). Additionally, we also probed for Pet1 mRNA (Fig. 4A), which encodes a key transcription factor controlling serotonergic identity (Hendricks et al., 1999). PET1 regulates transcription of Tph2, Sert, and other components of serotonergic identity (Spencer and Deneris, 2017). As expected, we found that all neurons expressing Tph 2 mRNA also expressed Pet1 mRNA (Fig. 4C,D, arrowheads); however, Kruskal-Wallis $H$ tests revealed no significant differences across experimental groups in levels of Tph2, Vglut3, or Pet1 mRNA (Fig. 4B). A small fraction (mean \pm SEM: $9.17 \pm 2.99 \%, n=5$ rats) of Pet1-expressing neurons did not contain Tph 2 mRNA (Fig. 4D, dashed outlines), which is consistent with previous observations in mice (Pelosi et al., 2014). On average, 19 of 206 Pet $1+$ neurons were Tph2- (numbers rounded to the nearest integer).

\section{Stressed rats display lower cFos expression in DRv neurons}

Neurotransmitter plasticity is linked to changes in neuronal activity (Borodinsky et al., 2004; Velázquez-Ulloa et al., 2011; Guemez-Gamboa et al., 2014; Meng et al., 2018). To specifically investigate whether non-serotonergic ( $\mathrm{TPH} 2-)$ neurons in the DRv, available for TPH2 recruitment in susceptible rats, experience any change in neuronal activity in response to social defeat, we assessed cFos expression by immunohistochemistry across stress conditions (Fig. 5A). The total number of cFos-immunoreactive neurons was decreased following stress (Fig. 5A, C; Kruskal-Wallis H test, $\left.\chi_{(2)}^{2}=11.325, p=0.003\right)$. Post hoc pairwise comparisons with Bonferroni correction showed that the decrease in cFos was significant in susceptible $(p=0.004)$ and resilient $(p=0.044)$ rats relative to controls. Specifically, this decrease occurred in TPH2- neurons (Fig. 5 B, D; Kruskal-Wallis $H$ test, $\left.\chi_{(2)}^{2}=17.967, p<0.001\right)$, both in susceptible $(p<$ $0.001)$ and resilient $(p=0.031)$ rats, whereas $c$ Fos expression was unchanged in TPH2+ neurons (Fig. $5 E$ ). We next tested the effects of activity manipulation in these neurons on DRv TPH2 phenotype and behavior. 
A
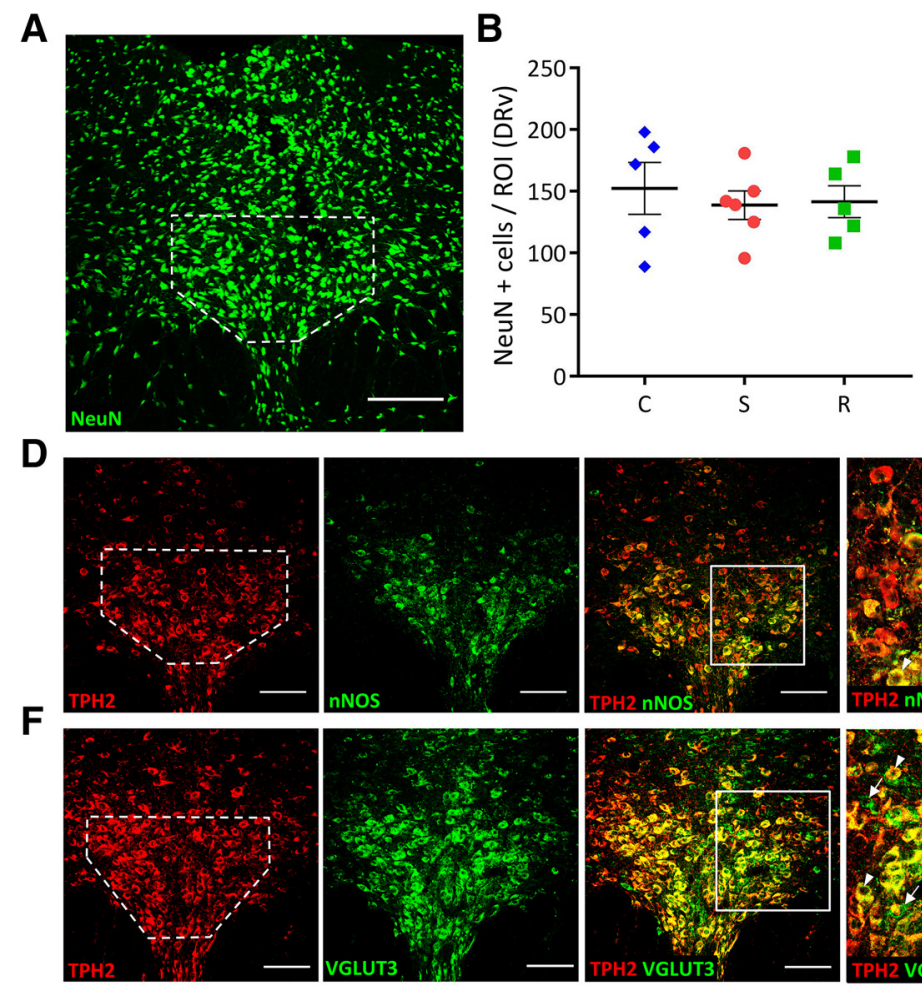

H
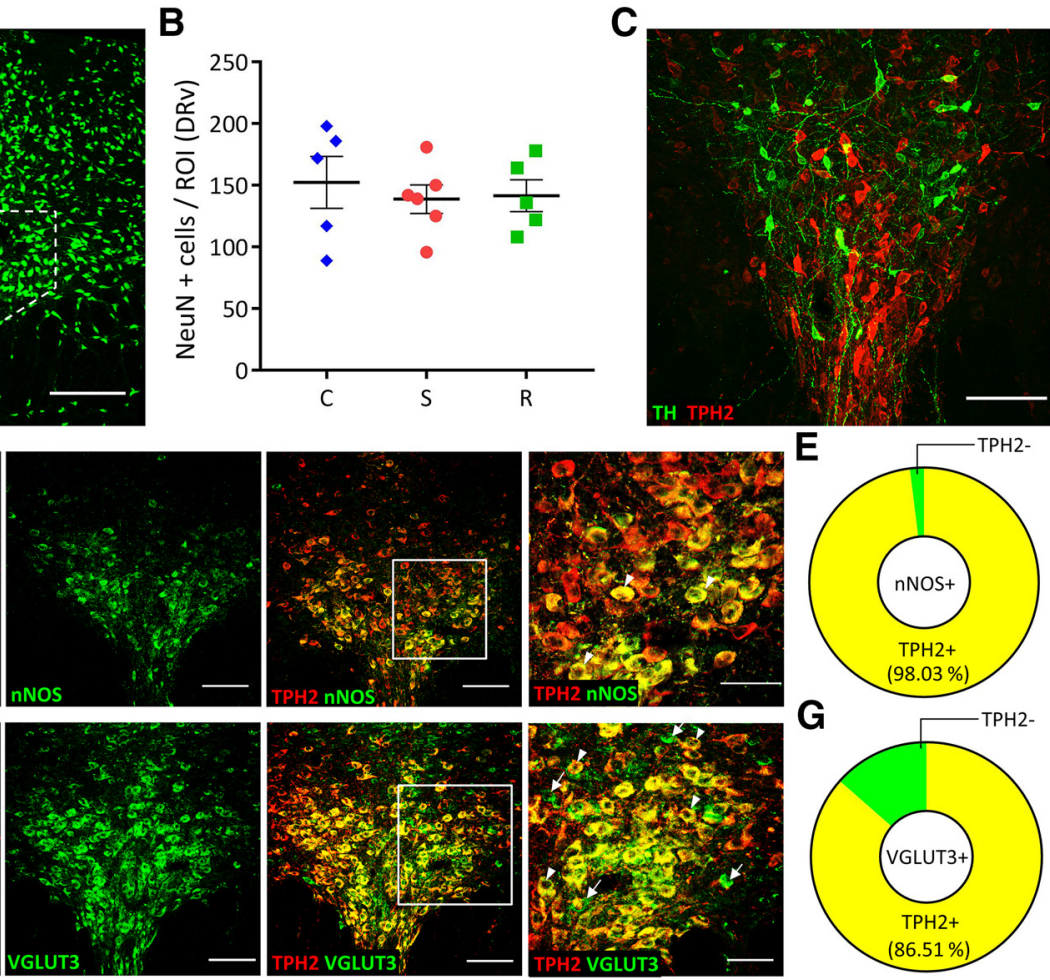

H

Control

Susceptible
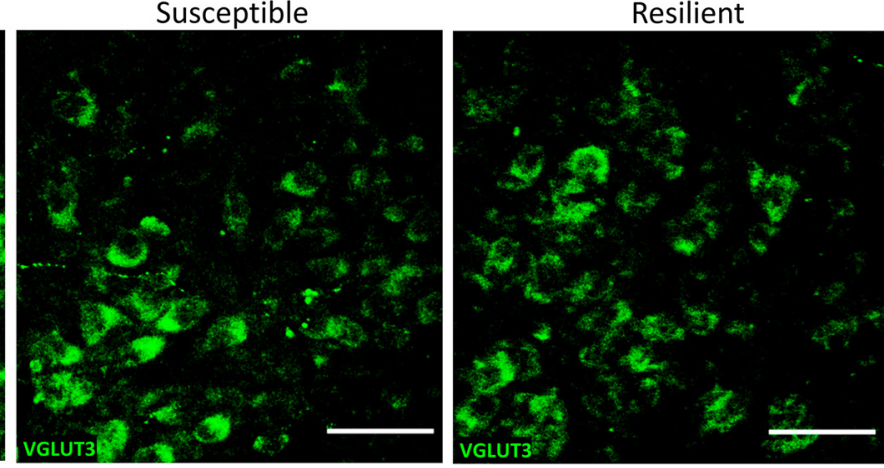

I

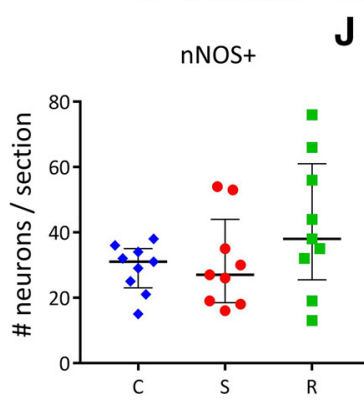

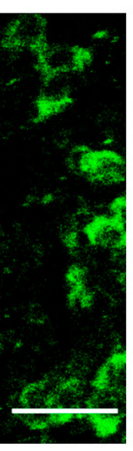

$\mathbf{J}$
nNOS+ TPH2+
K
L
L VGLUT3+ TPH2+

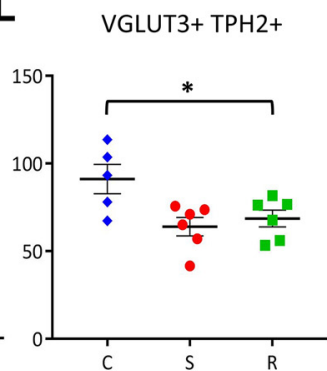

Figure 3. Stressed rats have fewer VGLUT3 + neurons in the DRv. $\boldsymbol{A}$, Representative image of a coronal DR section showing NeuN immunoreactivity. DRv margins outlined in white (as also in $\boldsymbol{D}$, F). Scale bar, $200 \mu \mathrm{m} . \boldsymbol{B}$, Quantification of NeuN + cells in control (C; blue diamonds, $n=5$ rats), susceptible ( $S$; red circles, $n=6$ rats), and resilient ( $R$; green squares, $n=5$ rats) groups. Rol, Region-of-interest. Counts were normalized to ROI area, averaged across rats per group and plotted as mean \pm SEM. C, Representative image of a coronal DR section showing dopaminergic (TH+; green) and serotonergic (TPH2+; red) neurons but no coexpression. Scale bar, $100 \mu \mathrm{m}$. D, Representative images of a coronal DR section showing nitrergic (nNOS) neurons coexpressing TPH2. Left to right: TPH2 (red), nNOS (green), merge (scale bar, $100 \mu \mathrm{m}$ ), and higher-magnification of ROl in merged image (scale bar, $25 \mu \mathrm{m}$ ). Arrowheads indicate nNOS + TPH2 + (yellow) coexpressing neurons. $\boldsymbol{E}$, Quantification of TPH2/nNOS coexpression in the DRv. Yellow sector indicates percentage of nNOS+ neurons coexpressing TPH2. Green sector indicates nNOS-only neurons. $\boldsymbol{F}$, Representative images of a coronal DR section showing glutamatergic (VGLUT3+) neurons coexpressing TPH2. Left to right: TPH2 (red), VGLUT3 (green), merge (scale bar, $100 \mu \mathrm{m}$ ), and higher magnification of ROl in merged image (scale bar, $50 \mu \mathrm{m}$ ). Arrowheads indicate VGLUT3 + TPH2 + (yellow) coexpressing neurons. G, Quantification of TPH2/VGLUT3 coexpression in the DRv. Yellow sector indicates percentage of VGLUT3 + neurons also expressing TPH2. Green sector indicates VGLUT3-only neurons. $\boldsymbol{H}$, VGLUT3 + neurons in the DRv of control, susceptible and resilient groups (scale bar, $50 \mu \mathrm{m}$ ). II, J, Quantification of nNOS + (I) and nNOS+ TPH2 + coexpressing $(J)$ neurons in the DRv of control (C; blue diamonds), susceptible (S; red circles), and resilient (R; green squares). Counts were obtained from three sections each from three rats per group and plotted as median with interquartile range. $K$, Quantification of DRv VGLUT3+ neurons. $L$, Quantification of DRvVGLUT3 + TPH2 + coexpressing neurons. $K, L$, Counts were averaged across rats (control: $n=5$, susceptible: $n=6$, resilient: $n=6$ ) and plotted as mean \pm SEM. ${ }^{*} p<0.05,{ }^{* *} p<0.01$. Graph symbols as defined in $I$. 
A
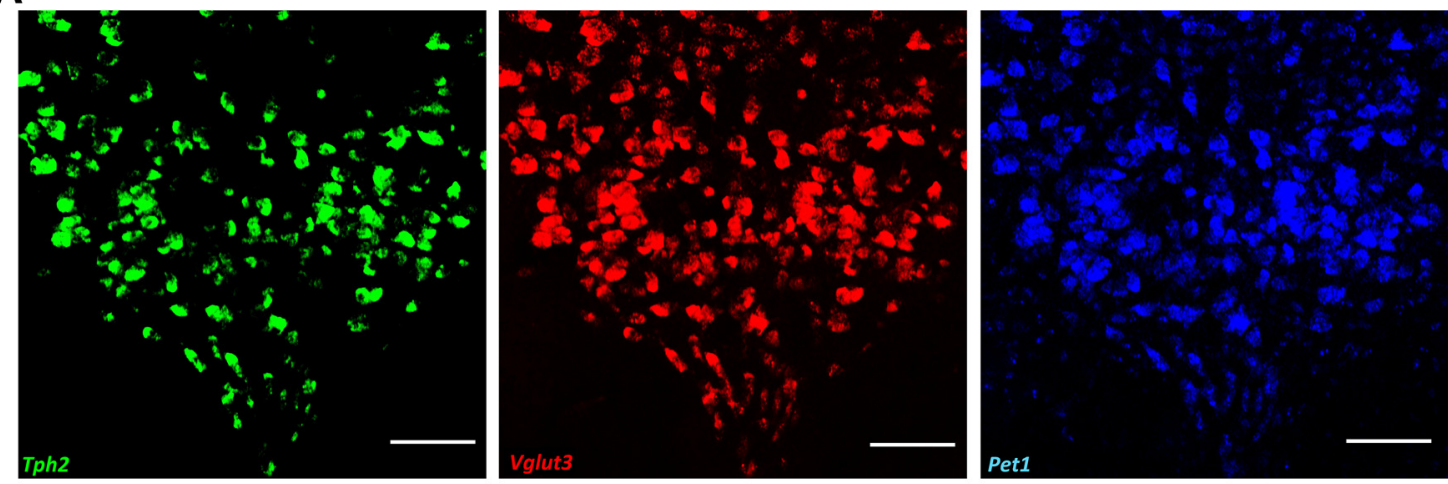

B
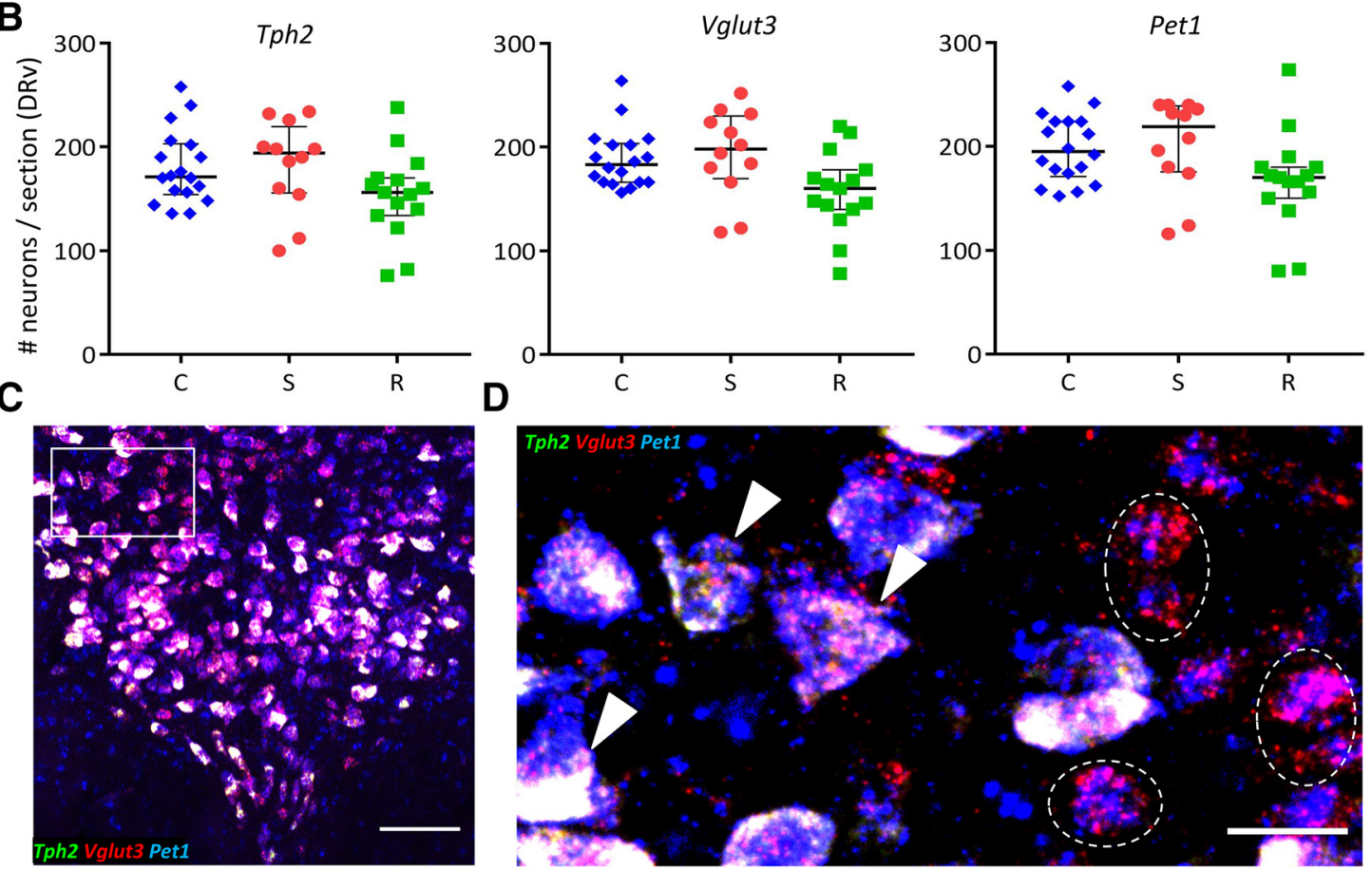

Figure 4. Number of neurons expressing Tph2, Vglut3, or Pet 1 mRNA does not differ across groups. A, Representative images of a coronal DR section processed for Tph2 (green), Vglut3 (red), and Pet1 (blue) triple in situ hybridization. Scale bars, $100 \mu \mathrm{m}$. B, Left to right, Quantification of number of neurons expressing Tph2, Vglut3, and Pet1 mRNA across control (C; blue diamonds, $n=5$ rats), susceptible ( $S$; red circles, $n=4$ rats) and resilient (R; green squares, $n=4$ rats) groups. Counts were obtained from 1 to 3 DRv sections per rat and plotted as median with interquartile range. $\boldsymbol{C}$, Merge of three channels shown in $\boldsymbol{A}$. Scale bar, $100 \mu \mathrm{m}$. D, Rol (rectangle in $\boldsymbol{C}$ ) at higher magnification showing triple labeled (arrowheads), and non-serotonergic Pet1 + Vglut3 + Tph2 - (dashed outline) neurons. Scale bar, $25 \mu \mathrm{m}$.

\section{Chronic activation of amygdalar $\mathrm{CRH}+$ neurons during} stress ameliorates anhedonia and prevents $\mathrm{TPH} 2$ induction To investigate whether TPH2 plasticity is activity-dependent and whether resilience is inducible in rats subjected to social stress, we manipulated neuronal activity in the DRv, by using DREADDs to drive the activity of one of its major inputs (Pollak Dorocic et al., 2014; Weissbourd et al., 2014), the central amygdala (CeA; Fig. 6A). In Crh-cre transgenic rats (Pomrenze et al., 2015), the CeA was bilaterally transfected with a Cre-dependent AAV vector encoding the excitatory DREADD receptor $(\mathrm{hM} 3 \mathrm{Dq})$ tagged with mCherry (Fig. 6A,B). A Cre-dependent AAV vector expressing GFP was used as a control (Fig. 6C). Serial sections through the CeA spaced $400 \mu \mathrm{m}$ apart, displayed fluorescent cell bodies and fibers localized to the lateral subnucleus of the central amygdala (CeL) without any ectopic expression, throughout its rostrocaudal extent (Fig. 6D). Rats were then trained and baselined in the ICSS procedure, habituated to intraperitoneal injections of saline and tested for anhedonia during $21 \mathrm{~d}$ social defeat with daily clozapine pretreatment. One-way repeated-measures ANOVA with Greenhouse-Geisser correction revealed that saline injections did not significantly alter reward thresholds (Fig. 6E). To test whether clozapine by itself affected reward thresholds relative to baseline over the $21 \mathrm{~d}$ period, the non-stressed control group expressing GFP virus was examined using a one-way repeatedmeasures ANOVA with Greenhouse-Geisser correction. The within-subjects effect of Day was not significant (Fig. 6F; $\left.F_{(3.324,16.620)}=2.349, p=0.105\right)$, indicating that clozapine does not produce off-target effects on reward-seeking behavior at the dose used. To test whether DREADD-mediated activation of the CeA affected reward thresholds in the absence of stress, thresholds of non-stressed controls expressing DREADDs and treated with clozapine for the $21 \mathrm{~d}$ period, were analyzed similarly. No significant effect of Day was observed (Fig. $6 F ; F_{(2.338,16.365)}=$ $0.724, p=0.520$ ), indicating that any effect of DREADD activation on reward thresholds in stressed rats was specific to the stress response and not a general reward-enhancing or reward- 
A

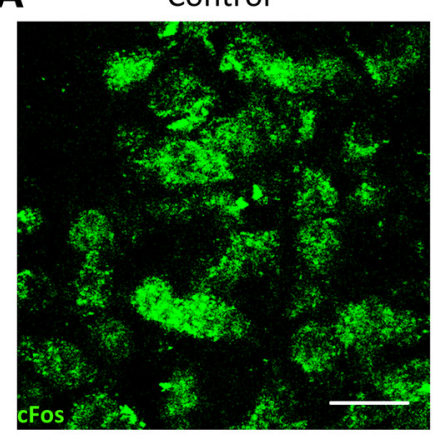

B

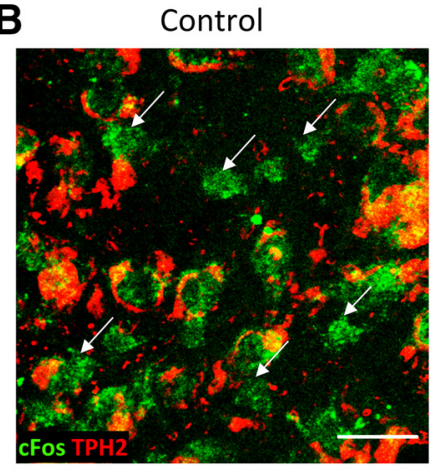

C

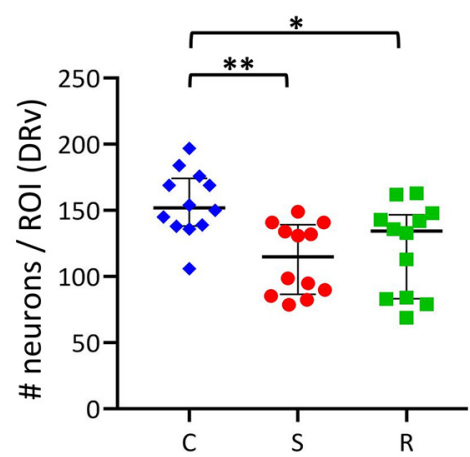

Susceptible

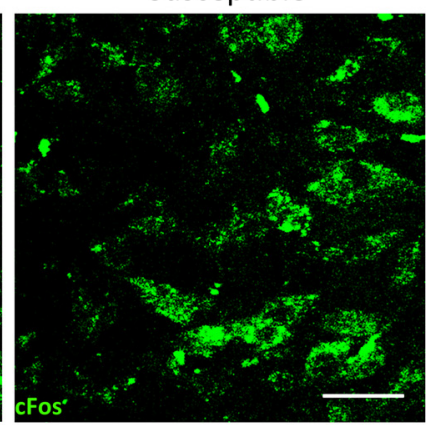

Susceptible

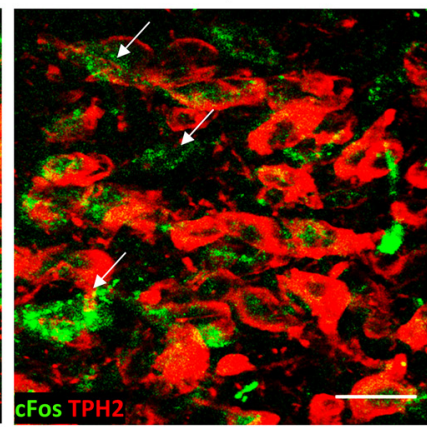

Resilient

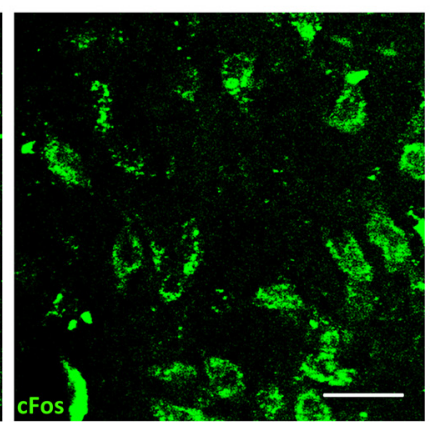

Resilient

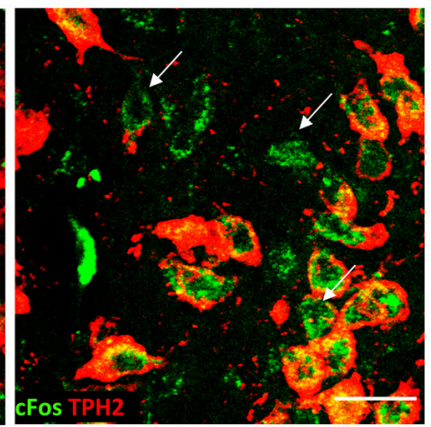

E

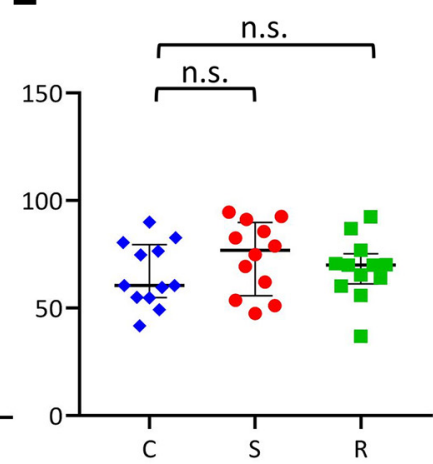

Figure 5. Stressed rats have fewer active TPH2 - neurons in the DRv. $A$, Left to right, Representative images of cFos immunoreactivity in DRv of control, susceptible and resilient rats. Scale bars, $25 \mu \mathrm{m}$. B, Left to right, Representative images of cFos immunoreactivity in TPH2 + (red) and TPH2 - (arrows) neurons in DRv across groups. Scale bars, $25 \mu \mathrm{m}$. C $\boldsymbol{E}$, Quantification of total cFos + $(\boldsymbol{C}), \mathrm{CFos}+\mathrm{TPH} 2-(\boldsymbol{D})$, and $\mathrm{CFos}+\mathrm{TPH} 2+(\boldsymbol{E})$ neuron number in control ( $\mathrm{C}$; blue diamonds), susceptible (S; red circles), and resilient (R; green squares) rats. Counts from four sections per rat were obtained from three rats per group, normalized to ROl area, and plotted as median and interquartile range. ${ }^{*} p<0.05$, ${ }^{* *} p<0.01$; n.s., not significant $(p>0.05)$.

diminishing effect of stimulating $\mathrm{CRH}$ neurons of the CeA. A two-way mixed ANOVA with Greenhouse-Geisser correction revealed that the two groups of non-stressed controls (GFP or hM3Dq virus injected) did not differ significantly from each other (Virus $\times$ Day interaction: $F_{(4.059,48.705)}=2.063, p=0.099$, main effect of Virus: $\left.F_{(1,12)}=2.296, p=0.156\right)$. Therefore, the two control groups were combined and used as a pooled control group for all subsequent analyses. Based on previous evidence that susceptibility or resilience manifests after chronic, but not acute, stress (Der-Avakian et al., 2014), which was supported by our observations (Fig. 1A,B), we analyzed the acute (Days 1-3) and chronic (Days 19-21) effects of social defeat on reward thresholds using a two-way mixed ANOVA (no violation of sphericity assumption, $\varepsilon=1$ ), with Period (acute or chronic) as the within-subjects factor and Group as the between-subjects factor (Fig. 6G). There was a significant interaction of Period $\times$ Group $\left(F_{(4,24)}=2.994, p=0.039\right)$ and significant main effects of Period $\left(F_{(1,24)}=5.329, p=0.030\right)$ and Group $\left(F_{(4,24)}=16.922, p=\right.$ 1.0E-6; Fig. $6 G)$.
Pairwise post hoc comparisons with Bonferroni correction showed that GFP susceptible and hM3Dq susceptible rats had significantly elevated reward thresholds relative to non-stressed controls after acute stress exposure (GFP susceptible: $p=0.001$, hM3Dq susceptible: $p=0.032$ ). However, as hypothesized, the effects of chronic stress differed from those of acute stress across groups. After chronic stress (Days 19-21), while the reward thresholds of GFP susceptible rats were significantly elevated relative to controls $(p=5.51 \mathrm{E}-7)$ and GFP resilient rats $(p=$ 0.001 ), the reward thresholds of hM3Dq susceptible rats were not significantly elevated relative to the hM3Dq resilient group ( $p=$ $0.115)$, but only elevated relative to control $(p=0.001)$. In other words, the reward thresholds of the DREADD-treated susceptible rats were statistically similar to the resilient group, suggesting that DREADD-activation of CeA CRH + neurons ameliorated chronic stress-induced anhedonia. A $k$ means cluster analysis (based on averaged thresholds of Days 19-21) classified all controls and resilient rats into a single cluster (Fig. $6 \mathrm{H}$ ). This cluster also included 3 of $5 \mathrm{hM} 3 \mathrm{Dq}$ susceptible, and 1 of 5 GFP suscep- 
A

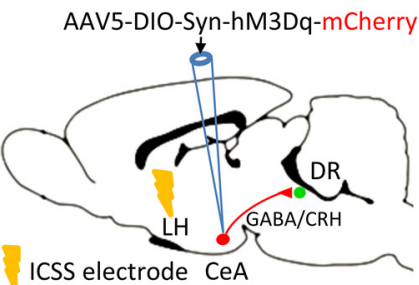

(Crh-cre)
B

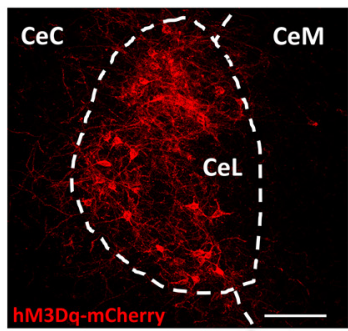

C

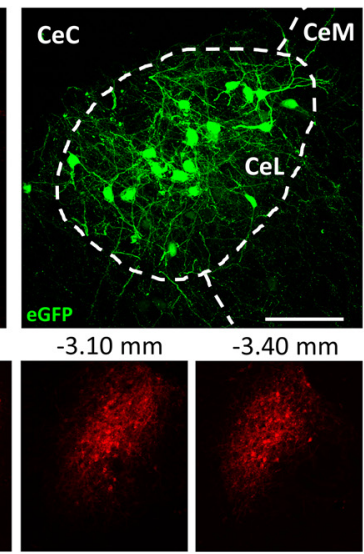

E
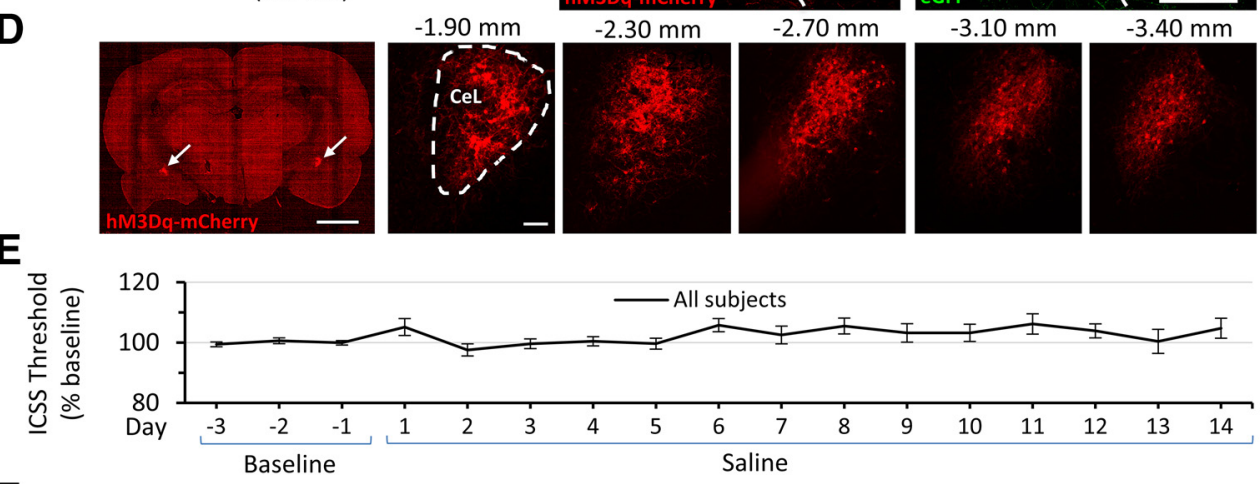

F

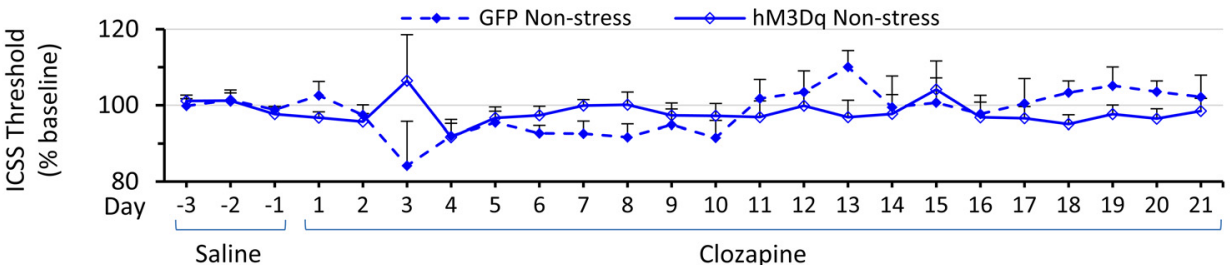

G

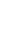
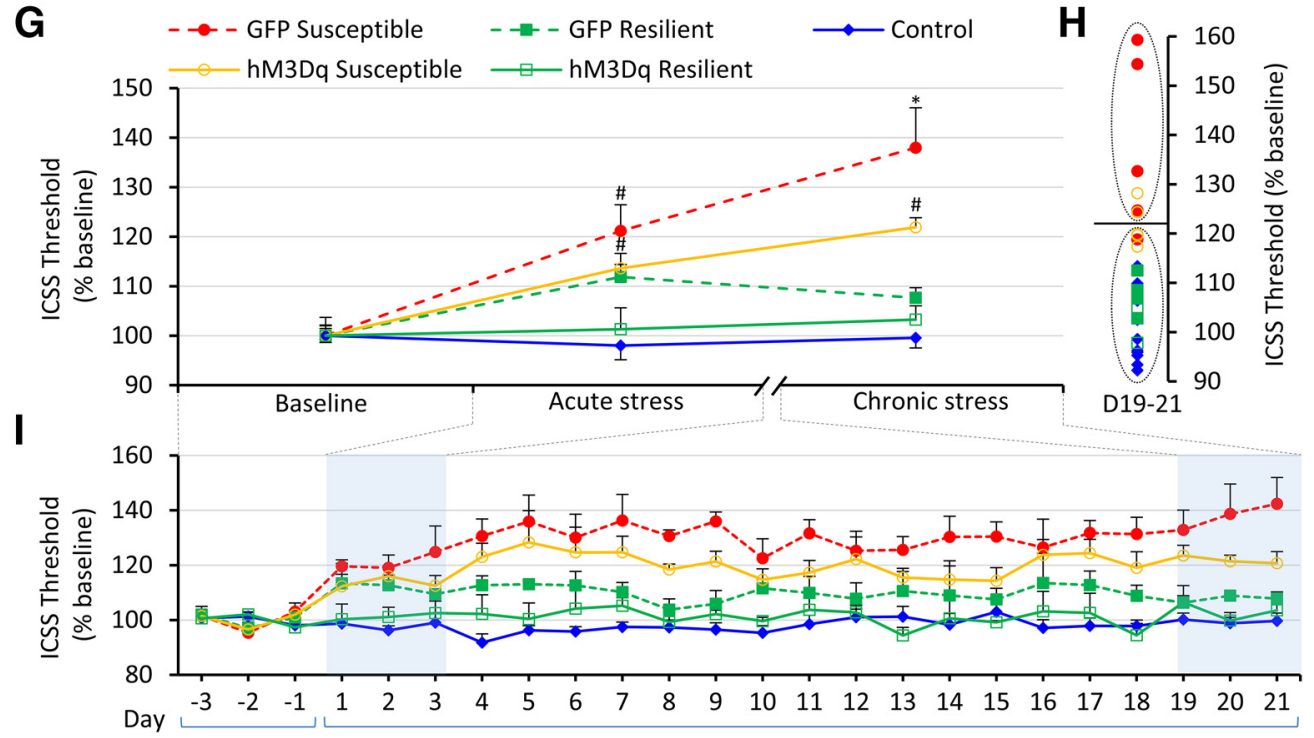

No stress + Saline

Social Defeat + Clozapine

Figure 6. Chronic activation of amygdalar $\mathrm{CRH}+$ neurons reduces reward thresholds. $A$, Diagram showing viral strategy for chemogenetic activation of CRH/GABA neurons in the CeA of $C r h$-cre rats. LH, Lateral hypothalamus. $\boldsymbol{B}, \boldsymbol{C}$, Expression of Cre-dependent mCherry-tagged excitatory DREADD (hM3Dq) virus $(\boldsymbol{B})$ or Cre-dependent eGFP virus $(\boldsymbol{C})$ in a $(r h-c r e$ rat. Cell bodies and fibers localized to the lateral subnucleus of the CeL (dashed outline). CeC and CeM denote capsular and medial subnuclei of the central amygdala, respectively. Scale bars, $100 \mu \mathrm{m}$. D, Left, Representative low-magnification $(4 \times)$ image of a coronal section through the central amygdala of a Crh-cre rat bilaterally transfected with Cre-dependent mCherry-tagged excitatory DREADD virus. $m$ Cherryexpressing cells seen in left and right CeL (arrows). Scale bar, $2.5 \mathrm{~mm}$. Right, Representative images $(20 \times)$ of the right CeL of the same rat showing anteroposterior spread of the virus. Numbers above each image indicate distance from bregma. Scale bar, $100 \mu \mathrm{m}$. E, Daily ICSS thresholds (mean across rats $+/-$ SEM) plotted as percentage of baseline for $3 \mathrm{~d}$ before saline intraperitoneal injections and for each day of saline treatment. All subjects $(n=29$ rats) are plotted. $F$, Daily ICSS thresholds (mean across rats + SEM) plotted as percentage of baseline, for $3 \mathrm{~d}$ of baseline before clozapine treatment and each day of $21 \mathrm{~d}$ clozapine treatment in non-stressed controls. GFP-expressing rats (solid diamonds, dotted line; $n=4$ ) and hM3Dq-expressing rats (hollow diamonds, solid line; $n=8$ ) are plotted. G, ICSS thresholds plotted as percentage of baseline (mean across rats \pm SEM) for baseline (average of Days -3 to -1 ) with saline treatment, acute (average of Days $1-3$ ) and chronic (average of Days 19-21) social defeat with clozapine treatment. GFP-expressing susceptible rats (red solid circles, dotted line; $n=5$ ), GFP-expressing resilient rats (green solid squares, dotted line; $n=4$ ), hM3Dq-expressing susceptible rats (orange hollow circles, solid line; $n=5$ ), and hM3Dq-expressing resilient rats (green hollow squares, solid line; $n=3$ ) are plotted. Significant $(p<0.05)$ post hoc pairwise comparisons for each time point are indicated above error bars. \# indicates a significant difference relative to control but not to other groups. * indicates a significant difference relative to control and resilient groups expressing the same virus. $\boldsymbol{H}, \mathrm{A} k$ means cluster analysis of Days $19-21$ averaged ICSS thresholds. Sample sizes (Figure legend continues.) 
tible rats. Other rats from the GFP susceptible and hM3Dq susceptible groups formed a separate cluster. Extended (daywise) reward thresholds during chemogenetic manipulation are shown in Figure $6 I$.

At the anatomical level, the number of DRv TPH2 + neurons showed significant differences across groups (Fig. 7A; $\left.F_{(4,24)}=6.337, p=0.001\right)$. Post hoc pairwise comparisons showed that the GFP susceptible group had a significantly elevated number of TPH2 + neurons relative to controls (Tukey's HSD: $p=0.041$ ), hM3Dq resilient (Tukey's HSD: $p=$ 0.014 ) and GFP resilient (Tukey's HSD: $p=0.001)$ groups, recapitulating the effects of social defeat in wild-type rats (Fig. $2 C, D)$ and demonstrating that clozapine alone had no effect on neurotransmitter plasticity in the DR following social defeat. Interestingly, the hM3Dq susceptible group did not display an elevated number of $\mathrm{TPH} 2+$ neurons relative to control (Tukey's HSD: $p=9.99 \mathrm{E}-1$ ), hM3Dq resilient (Tukey's HSD: $p=0.620$ ), or GFP resilient (Tukey's HSD: $p=0.142$ ) groups, indicating that manipulation of DR activity via CeA activation prevented stress-induced increase in $\mathrm{TPH} 2+$ neuron number. The lower extent of anhedonia in the hM3Dq susceptible rats, compared with GFP susceptible rats (Fig. 6G-I) is reflected in the lower TPH2+ neuron numbers in the hM3Dq susceptible group (Fig. 7A). $\mathrm{TPH} 2+$ neuron number in the DRv and ICSS thresholds were significantly positively correlated in all stressed rats (wild-type and transgenic) used in this study (Fig. $7 B$; Pearson's $r=0.743, p=$ $3.0 \mathrm{E}-6, n=30)$. This suggests that the number of TPH $2+$ neurons in the DRv varies linearly with susceptibility to stress-induced anhedonia, providing a quantitative, neurotransmitter-type-specific, molecular characterization of individual differences in behavioral susceptibility to chronic stress.

\section{Discussion}

Studies in rodent models have shown that serotonergic molecular machinery is upregulated in the DR after both chronic (Adell et al., 1988; Zhang et al., 2012; Donner et al., 2016) and acute stress (Donner et al., 2018). However, they did not specifically address differences between rodents that are susceptible or resilient to chronic stress-induced anhedonia, or whether this upregulation occurs in identified classes of neurons expressing specific neurotransmitters. Other molecular adaptations investigated in the context of susceptibility/resilience such as synaptic excitability in the nucleus accumbens (Krishnan et al., 2007; Vialou et al., 2010), VTA (Krishnan et al., 2007), medial prefrontal cortex (Covington et al., 2010; Lehmann and Herkenham, 2011), and hypothalamic pituitary adrenal (HPA) axis activation (Elliott et al., 2010) have not been demonstrated to be specific to anhedonia. Furthermore, neurotransmitter plasticity (Dulcis and Spitzer, 2012) as a mech-

$\leftarrow$

(Figure legend continued.) and graph symbols as in G.I, Effect of DREADD stimulation of CeA $\mathrm{CRH}+$ neurons on ICSS thresholds during social defeat. Daily ICSS thresholds (mean across rats + SEM) plotted as percentage of baseline, for $3 \mathrm{~d}$ of baseline before clozapine treatment/social defeat and for each day of $21 \mathrm{~d}$ clozapine treatment/social defeat. Graph symbols as in G. Days used to compute averages for acute and chronic stress in $\mathbf{G}$ are highlighted in blue.

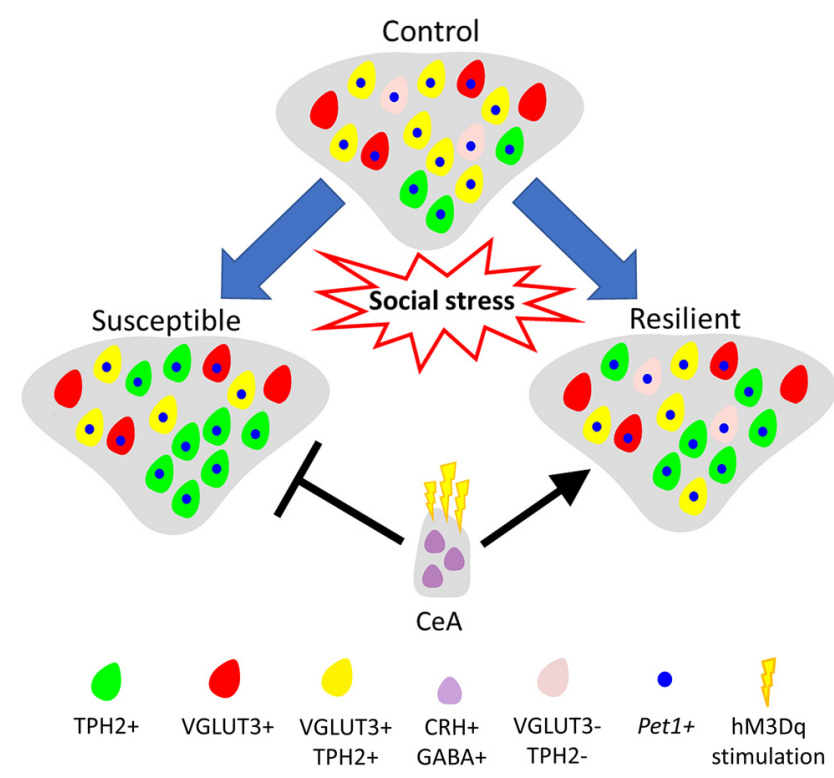

Figure 8. Model of neurotransmitter plasticity in the DRv in response to chronic social stress. In response to chronic social stress, neurotransmitter plasticity occurs in the DRv of stressed rats. Rats susceptible to stress-induced anhedonia gain TPH2 and lose VGLUT3, whereas resilient rats only lose VGLUT3. Loss of VGLUT3 leads to lower coexpression of the two markers in both conditions. The plasticity occurs in neurons expressing Pet1 transcripts. Activation of $\mathrm{CRH}+$ neurons of the CeA promotes resilience and blocks susceptibility.

anism to explain susceptibility/resilience to anhedonia has not been explored previously.

Our results reveal that chronic social defeat induces an increase in the number of TPH2 + neurons without affecting the total number of DRv neurons in susceptible rats, indicating that differentiated $\mathrm{TPH} 2-$ neurons in the DR are recruited to additionally express TPH2. A concomitant reduction in VGLUT3+ neurons in the DRv of all stressed rats suggests that stressinduced anhedonia in susceptible animals is an example of transmitter "switching" (Spitzer, 2017) driven by stress. These findings point to a mechanism of functional plasticity, i.e., neurotransmitter plasticity in response to chronic stress that is 
associated with vulnerability to stress-induced anhedonia. Neurotransmitter plasticity has been shown to occur in response to other forms of stress such as altered photoperiod exposure (Dulcis et al., 2013; Young et al., 2018) or exposure to psychostimulants such as nicotine (Romoli et al., 2019) and methamphetamine (Kesby et al., 2017). Interestingly, the change in number of TPH2 + neurons occurred exclusively in the DRv, but not in the other subnuclei of the mid-rostrocaudal DR. This is consistent with what is known about the afferent and efferent connectivity of the DRv. The DRv receives inputs from the lateral hypothalamus, central amygdala and orbitofrontal cortex (Peyron et al., 1997) and projects to orbitofrontal and other cortical areas (Ren et al., 2018) and the VTA (Qi et al., 2014). All of these areas are implicated either in reward sensing and integration (Rolls, 2000; Gottfried et al., 2003; van Zessen et al., 2012), reward-based decision-making (Bechara et al., 2000), or stress processing (Swiergiel et al., 1993; Hsu et al., 1998; Bonnavion et al., 2015). The DRv is therefore, a critical hub that regulates stress and reward-related behaviors by serotonergic neuromodulation of multiple target areas. Plasticity in the DRv could impact the activity and function of these regions, subsequently affecting behavior.

The increase in number of TPH2 + neurons in the anhedonic condition (susceptible rats) is consistent with increased TPH2 immunoreactivity and mRNA expression observed after exposure to stress in animals (Poeggel et al., 2003; Amat et al., 2010; Donner et al., 2018) and in brains of depressed patients who committed suicide (Underwood et al., 1999; Boldrini et al., 2005; Bach-Mizrachi et al., 2008). Our findings are the first evidence in an animal model, that stress-induced increase in TPH2 in the DR does not result merely from an increased expression within preexisting serotonergic neurons, but is a result of previously nonserotonergic neurons gaining TPH2 expression. These findings add an important layer of complexity, i.e., the plasticity of neuron number, to stress-induced molecular changes. There is also ample electrophysiological evidence to suggest that serotonin exerts complex neuromodulation of the VTA in conjunction with glutamate and dopamine (Pessia et al., 1994; Gervais and Rouillard, 2000; Guiard et al., 2008; Liu et al., 2014; Belmer et al., 2016; Wang et al., 2019). Therefore, an increase in TPH2 + neurons in the DRv may lead to reduced reward function in the VTA. Details of the mechanisms by which increased serotonergic transmission from the DR contributes to symptoms of depression, including anhedonia, are unknown, but potential explanations are discussed by Andrews et al. (2015).

Our results provide some insight into the neurotransmitter identity of the neurons that gain TPH2. A 98\% nNOS+ TPH $2+$ coexpression indicated that there were not enough nNOS+ $\mathrm{TPH} 2-$ neurons to account for the rise in TPH $2+$ numbers in susceptible rats. Within the glutamatergic (VGLUT3+) population, a decrease in both susceptible and resilient rats occurring within VGLUT3 + TPH2 + coexpressing neurons indicates that plasticity in VGLUT3 expression segregates stressed versus nonstressed, but not susceptible versus resilient rats. These results exclude dopamine-, nitric oxide- and glutamate-expressing neurons as candidates for the reserve pool (Dulcis and Spitzer, 2012) acquiring a TPH2 + phenotype in susceptible rats. A fraction of GABA-ergic neurons in the DRv (Fu et al., 2010; Bang and Commons, 2012) could be one such reserve pool to investigate in the future. The absence of changes in Tph2 or Vglut3 at the transcript level (Fig. 4) suggests that the observed differences in the number of TPH2 + and VGLUT3+ neurons across groups (Fig. 3) arose from differences at the level of post-transcriptional or translational regulation similar to miRNA-mediated dopamine/GABA switching in response to social cues in the developing amphibian olfactory bulb (Dulcis et al., 2017). Post-translational modifications such as TPH2 phosphorylation that affect enzyme stability (Murphy et al., 2008) and activity (Banik et al., 1997) may also regulate the observed neurotransmitter plasticity.

Neuronal activity, as measured by cFos expression, was decreased specifically in DRv TPH2- neurons following chronic stress in all stressed rats. This suggests that DRv is inhibited after chronic stress regardless of whether the rat is susceptible or resilient to stress-induced anhedonia, a pattern similar to the VGLUT3+ phenotype. Since the rats were perfused $6 \mathrm{~h}$ after the social defeat encounter on Day 21, differences in cFos expression presumably reflect changes in the basal activity of the DR in rats subjected to chronic social defeat, diminishing the possibility that the observed effects on cFos expression occurred due to the acute effects of social defeat on Day 21. The DRv receives projections from the CeA containing GABA and $\mathrm{CRH}$, which modulate the activity of both serotonergic and non-serotonergic neurons (Pollak Dorocic et al., 2014; Weissbourd et al., 2014; Pomrenze et al., 2015) in the DR, via CRHR1 and CRHR2 receptors (Lowry et al., 2000; Day et al., 2004; Donner et al., 2016). Moreover, the CeA responds differently to acute versus chronic social defeat (Martinez et al., 1998b, 2002). Further, CRH in particular is implicated in the development of depression-like phenotypes in rodents in response to uncontrollable stressors (Maier and Watkins, 2005). These reports, which clearly indicated that the $\mathrm{CRH}+$ neurons in the CeA form a strong input to the DRv involved in regulation of stress and reward-related behavior, motivated our choice to manipulate their activity. Lack of a significant difference between hM3Dq-treated susceptible and resilient rats at the end of chronic social defeat (Days 19-21), suggested an antidepressant effect of activating CeA CRH + neurons. It is likely that other brain regions involved in stress-processing and resilience, such as the medial prefrontal cortex (Amat et al., 2005), play a role in inducing resilience. Simultaneous activation of such regions might result in stronger effects on reward thresholds and resilience than what was achieved with CeA manipulation alone. The lack of a significant increase in the number of DRv TPH2 + neurons observed in $\mathrm{hM} 3 \mathrm{Dq}$-treated rats exposed to social defeat revealed the activity-dependent nature of resilience and its association with neurotransmitter phenotype in the DRv. Considering previous reports that higher doses (1-20 mg/kg) of clozapine, an atypical antipsychotic, affect normal locomotor behavior (Gomez et al., 2017) and cFos expression in rat models of stress (Osacka et al., 2018; Stanisavljević et al., 2019), we deliberately used a lower dose of clozapine $(0.1 \mathrm{mg} / \mathrm{kg})$ to activate the DREADD receptor. At this dose, we did not observe any effect of clozapine administration on ICSS thresholds (Fig. 6E) in rats expressing the control virus, consistent with prior observations that clozapine does not affect ICSS thresholds even at $4 \mathrm{mg} / \mathrm{kg}$ (Amitai et al., 2009). However, in rats expressing the DREADD receptor this dose was sufficient to produce behavioral and molecular effects (Fig. 6G-I).

In conclusion, our findings begin to reveal a possible model of neurotransmitter plasticity involved in the regulation of resilience to social stress (Fig. 8). Susceptible animals gain TPH2 expression in the DRv in response to chronic stress, while resilient animals do not. VGLUT3 is lost in susceptible and resilient animals, largely by neurons that coexpress both markers. This plasticity of expression occurs at the protein level, presumably by post-transcriptional or translational regulation since the number of neurons making corresponding mRNA transcripts was unchanged. Activation of $\mathrm{CRH}+$ neurons in the CeA, which form a 
major input to the DR, modulates the effects of social stress on $\mathrm{DR}$ activity by preventing TPH2+ induction. This consequently prevents or ameliorates anhedonia, promoting resilience.

Knowledge of the molecular signature of susceptibility/resilience to chronic stress-induced anhedonia and the activitydependent induction of resilience could both be harnessed in the future to develop novel treatment strategies to elicit resilience and ameliorate stress-related disorders.

\section{References}

Abrams JK, Johnson PL, Hollis JH, Lowry CA (2004) Anatomic and functional topography of the dorsal raphe nucleus. Ann NY Acad Sci 1018:46-57.

Abumaria N, Rygula R, Hiemke C, Fuchs E, Havemann-Reinecke U, Rüther E, Flügge G (2007) Effect of chronic citalopram on serotonin-related and stress-regulated genes in the dorsal raphe nucleus of the rat. Eur Neuropsychopharmacology 17:417-429.

Adamec R, Burton P, Blundell J, Murphy DL, Holmes A (2006) Vulnerability to mild predator stress in serotonin transporter knock-out mice. Behav Brain Res 170:126-140.

Adell A, Garcia-Marquez C, Armario A, Gelpi E (1988) Chronic stress increases serotonin and noradrenaline in rat brain and sensitizes their responses to a further acute stress. J Neurochem 50:1678-1681.

Alexander L, Gaskin PLR, Sawiak SJ, Fryer TD, Hong YT, Cockcroft GJ, Clarke HF, Roberts AC (2019) Fractionating blunted reward processing characteristic of anhedonia by over-activating primate subgenual anterior cingulate cortex. Neuron 101:307-320.e6.

Amat J, Baratta MV, Paul E, Bland ST, Watkins LR, Maier SF (2005) Medial prefrontal cortex determines how stressor controllability affects behavior and dorsal raphe nucleus. Nat Neurosci 8:365-371.

Amat J, Aleksejev RM, Paul E, Watkins LR, Maier SF (2010) Behavioral control over shock blocks behavioral and neurochemical effects of later social defeat. Neuroscience 165:1031-1038.

American Psychiatric Association (2013) Diagnostic and statistical manual of mental disorders, Ed 5. Washington, DC: American Psychiatric.

Amitai N, Semenova S, Markou A (2009) Clozapine attenuates disruptions in response inhibition and task efficiency induced by repeated phencyclidine administration in the intracranial self-stimulation procedure. Eur J Pharmacol 602:78-84.

Andrews PW, Bharwani A, Lee KR, Fox M, Thomson JA Jr (2015) Is serotonin an upper or a downer? The evolution of the serotonergic system and its role in depression and the antidepressant response. Neurosci Biobehav Rev 51:164-188.

Bach-Mizrachi H, Underwood MD, Tin A, Ellis SP, Mann JJ, Arango V (2008) Elevated expression of tryptophan hydroxylase-2 mRNA at the neuronal level in the dorsal and median raphe nuclei of depressed suicides. Mol Psychiatry 13:507-513.

Backström T, Winberg S (2017) Serotonin coordinates responses to social stress: what we can learn from fish. Front Neurosci 11:595.

Baker KG, Halliday GM, Törk I (1990) Cytoarchitecture of the human dorsal raphe nucleus. J Comp Neurol 301:147-161.

Baker KG, Halliday GM, Hornung JP, Geffen LB, Cotton RG, Törk I (1991) Distribution, morphology and number of monoamine-synthesizing and substance $\mathrm{P}$-containing neurons in the human dorsal raphe nucleus. Neuroscience 42:757-775.

Bang SJ, Commons KG (2012) Forebrain GABAergic projections from the dorsal raphe nucleus identified by using GAD67-GFP knock-in mice. J Comp Neurol 520:4157-4167.

Banik U, Wang GA, Wagner PD, Kaufman S (1997) Interaction of phosphorylated tryptophan hydroxylase with 14-3-3 proteins. J Biol Chem 272:26219-26225.

Bechara A, Damasio H, Damasio AR (2000) Emotion, decision making and the orbitofrontal cortex. Cereb Cortex 10:295-307.

Belmer A, Lanoue V, Patkar O, Bartlett SE (2016) Excitatory/inhibitory balance of serotonergic axon connectivity in the brain. J Neurol Neuromed 1:18-22.

Benmansour S, Cecchi M, Morilak DA, Gerhardt GA, Javors MA, Gould GG, Frazer A (1999) Effects of chronic antidepressant treatments on serotonin transporter function, density, and mRNA level. J Neurosci 19: 10494-10501.

Berton O, Aguerre S, Sarrieau A, Mormede P, Chaouloff F (1997) Differential effects of social stress on central serotonergic activity and emotional reactivity in Lewis and spontaneously hypertensive rats. Neuroscience 82:147-159.

Boldrini M, Underwood MD, Mann JJ, Arango V (2005) More tryptophan hydroxylase in the brainstem dorsal raphe nucleus in depressed suicides. Brain Res 1041:19-28.

Bonanno GA, Wortman CB, Lehman DR, Tweed RG, Haring M, Sonnega J, Carr D, Nesse RM (2002) Resilience to loss and chronic grief: a prospective study from preloss to 18 -months postloss. J Pers Soc Psychol 83:1150-1164.

Bonnavion P, Jackson AC, Carter ME, de Lecea L (2015) Antagonistic interplay between hypocretin and leptin in the lateral hypothalamus regulates stress responses. Nat Commun 6:6266.

Borodinsky LN, Root CM, Cronin JA, Sann SB, Gu X, Spitzer NC (2004) Activity-dependent homeostatic specification of transmitter expression in embryonic neurons. Nature 429:523-530.

Carlezon WA Jr, Chartoff EH (2007) Intracranial self-stimulation (ICSS) in rodents to study the neurobiology of motivation. Nat Protoc 2:2987-2995.

Chaouloff F, Berton O, Mormède P (1999) Serotonin and stress. Neuropsychopharmacology 21:28S-32S.

Chaudhury D, Walsh JJ, Friedman AK, Juarez B, Ku SM, Koo JW, Ferguson D, Tsai HC, Pomeranz L, Christoffel DJ, Nectow AR, Ekstrand M, Domingos A, Mazei-Robison MS, Mouzon E, Lobo MK, Neve RL, Friedman JM, Russo SJ, Deisseroth K, et al. (2013) Rapid regulation of depressionrelated behaviours by control of midbrain dopamine neurons. Nature 493:532-536.

Chocyk A, Przyborowska A, Dudys D, Majcher I, Maćkowiak M, Wędzony K (2011) The impact of maternal separation on the number of tyrosine hydroxylase-expressing midbrain neurons during different stages of ontogenesis. Neuroscience 182:43-61.

Chugani DC, Muzik O, Rothermel R, Behen M, Chakraborty P, Mangner T, da Silva EA, Chugani HT (1997) Altered serotonin synthesis in the dentatothalamocortical pathway in autistic boys. Ann Neurol 42:666-669.

Covington HE 3rd, Lobo MK, Maze I, Vialou V, Hyman JM, Zaman S, LaPlant Q, Mouzon E, Ghose S, Tamminga CA, Neve RL, Deisseroth K, Nestler EJ (2010) Antidepressant effect of optogenetic stimulation of the medial prefrontal cortex. J Neurosci 30:16082-16090.

Dahlström A, Fuxe K (1964) Evidence for the existence of monoaminecontaining neurons in the central nervous system: I. Demonstration of monoamines in the cell bodies of brain stem neurons. Acta Physiol Scand Suppl 232:1-55.

Day HE, Greenwood BN, Hammack SE, Watkins LR, Fleshner M, Maier SF, Campeau S (2004) Differential expression of 5HT-1A, alpha 1b adrenergic, CRF-R1, and CRF-R2 receptor mRNA in serotonergic, gammaaminobutyric acidergic, and catecholaminergic cells of the rat dorsal raphe nucleus. J Comp Neurol 474:364-378.

Demarque M, Spitzer NC (2010) Activity-dependent expression of Lmxlb regulates specification of serotonergic neurons modulating swimming behavior. Neuron 67:321-334.

Der-Avakian A, Markou A (2010) Neonatal maternal separation exacerbates the reward-enhancing effect of acute amphetamine administration and the anhedonic effect of repeated social defeat in adult rats. Neuroscience 170:1189-1198.

Der-Avakian A, Mazei-Robison MS, Kesby JP, Nestler EJ, Markou A (2014) Enduring deficits in brain reward function after chronic social defeat in rats: susceptibility, resilience, and antidepressant response. Biol Psychiatry 76:542-549.

Der-Avakian A, Barnes SA, Markou A, Pizzagalli DA (2015) Translational assessment of reward and motivational deficits in psychiatric disorders. In: Translational neuropsychopharmacology (Robbins TW, Sahakian BJ, eds), pp 231-262. Cham: Springer.

Dhir A, Kulkarni SK (2007) Involvement of nitric oxide (NO) signaling pathway in the antidepressant action of bupropion, a dopamine reuptake inhibitor. Eur J Pharmacol 568:177-185.

Donner NC, Siebler PH, Johnson DT, Villarreal MD, Mani S, Matti AJ, Lowry CA (2016) Serotonergic systems in the balance: CRHR1 and CRHR2 differentially control stress-induced serotonin synthesis. Psychoneuroendocrinology 63:178-190.

Donner NC, Kubala KH, Hassell JE Jr, Lieb MW, Nguyen KT, Heinze JD, Drugan RC, Maier SF, Lowry CA (2018) Two models of inescapable stress increase tph 2 mRNA expression in the anxiety-related dorsomedial part of the dorsal raphe nucleus. Neurobiol Stress 8:68-81. 
Dulcis D (2016) The ever-changing brain: clinical implications. J Chem Neuroanat 73:1-2.

Dulcis D, Spitzer NC (2008) Illumination controls differentiation of dopamine neurons regulating behaviour. Nature 456:195-201.

Dulcis D, Spitzer NC (2012) Reserve pool neuron transmitter respecification: novel neuroplasticity. Dev Neurobiol 72:465-474.

Dulcis D, Jamshidi P, Leutgeb S, Spitzer NC (2013) Neurotransmitter switching in the adult brain regulates behavior. Science 340:449-453.

Dulcis D, Lippi G, Stark CJ, Do LH, Berg DK, Spitzer NC (2017) Neurotransmitter switching regulated by miRNAs controls changes in social preference. Neuron 95:1319-1333.e5.

Elliott E, Ezra-Nevo G, Regev L, Neufeld-Cohen A, Chen A (2010) Resilience to social stress coincides with functional DNA methylation of the crf gene in adult mice. Nat Neurosci 13:1351-1353.

Ener RA, Meglathery SB, Van Decker WA, Gallagher RM (2003) Serotonin syndrome and other serotonergic disorders. Pain Med 4:63-74.

Fu W, Le Maître E, Fabre V, Bernard JF, David Xu ZQD, Hökfelt T (2010) Chemical neuroanatomy of the dorsal raphe nucleus and adjacent structures of the mouse brain. J Comp Neurol 518:3464-3494.

Gervais J, Rouillard C (2000) Dorsal raphe stimulation differentially modulates dopaminergic neurons in the ventral tegmental area and substantia nigra. Synapse 35:281-291.

Gholami A, Zarrindast MR, Sahraei H, Haerri-Rohani A (2003) Nitric oxide within the ventral tegmental area is involved in mediating morphine reward. Eur J Pharmacol 458:119-128.

Gomez JL, Bonaventura J, Lesniak W, Mathews WB, Sysa-Shah P, Rodriguez LA, Ellis RJ, Richie CT, Harvey BK, Dannals RF, Pomper MG, Bonci A, Michaelides M (2017) Chemogenetics revealed: DREADD occupancy and activation via converted clozapine. Science 357:503-507.

Gottfried JA, O'Doherty J, Dolan RJ (2003) Encoding predictive reward value in human amygdala and orbitofrontal cortex. Science 301:1104-1107.

Grahn RE, Will MJ, Hammack SE, Maswood S, McQueen MB, Watkins LR, Maier SF (1999) Activation of serotonin-immunoreactive cells in the dorsal raphe nucleus in rats exposed to an uncontrollable stressor. Brain Res 826:35-43.

Grandjean J, Corcoba A, Kahn MC, Upton AL, Deneris ES, Seifritz E, Helmchen F, Mann EO, Rudin M, Saab BJ (2019) A brain-wide functional map of the serotonergic responses to acute stress and fluoxetine. Nat Commun 10:350.

Grimm D, Lee JS, Wang L, Desai T, Akache B, Storm TA, Kay MA (2008) In vitro and in vivo gene therapy vector evolution via multispecies interbreeding and retargeting of adeno-associated viruses. J Virol 82:5887-5911.

Guemez-Gamboa A, Xu L, Meng D, Spitzer NC (2014) Non-cellautonomous mechanism of activity-dependent neurotransmitter switching. Neuron 82:1004-1016.

Guiard BP, El Mansari M, Merali Z, Blier P (2008) Functional interactions between dopamine, serotonin and norepinephrine neurons: an in-vivo electrophysiological study in rats with monoaminergic lesions. Int J Neuropsychopharmacol 11:625-639.

Gutknecht L, Popp S, Waider J, Sommerlandt FM, Göppner C, Post A, Reif A, van den Hove D, Strekalova T, Schmitt A, Colaso MB, Sommer C, Palme $\mathrm{R}$, Lesch KP (2015) Interaction of brain 5-HT synthesis deficiency, chronic stress and sex differentially impact emotional behavior in Tph2 knockout mice. Psychopharmacology 232:2429-2441.

Hale MW, Shekhar A, Lowry CA (2012) Stress-related serotonergic systems: implications for symptomatology of anxiety and affective disorders. Cell Mol Neurobiol 32:695-708.

Hariri AR, Mattay VS, Tessitore A, Kolachana B, Fera F, Goldman D, Egan MF, Weinberger DR (2002) Serotonin transporter genetic variation and the response of the human amygdala. Science 297:400-403.

Hendricks T, Francis N, Fyodorov D, Deneris ES (1999) The ETS domain factor pet-1 is an early and precise marker of central serotonin neurons and interacts with a conserved element in serotonergic genes. J Neurosci 19:10348-10356.

Herrmann MJ, Huter T, Müller F, Mühlberger A, Pauli P, Reif A, Renner T, Canli T, Fallgatter AJ, Lesch KP (2006) Additive effects of serotonin transporter and tryptophan hydroxylase-2 gene variation on emotional processing. Cereb Cortex 17:1160-1163.

Holmes A, Yang RJ, Lesch KP, Crawley JN, Murphy DL (2003) Mice lacking the serotonin transporter exhibit 5-HT 1A receptor-mediated abnormalities in tests for anxiety-like behavior. Neuropsychopharmacology 28 : 2077-2088.
Hornung JP (2003) The human raphe nuclei and the serotonergic system. J Chem Neuroanat 26:331-343.

Hsu DT, Chen FL, Takahashi LK, Kalin NH (1998) Rapid stress-induced elevations in corticotropin-releasing hormone mRNA in rat central amygdala nucleus and hypothalamic paraventricular nucleus: an in situ hybridization analysis. Brain Res 788:305-310.

Iglewicz B, Hoaglin DC (1993) How to detect and handle outliers. In: The ASQC basic references in quality control: statistical techniques (Mykytka EF, ed), pp 11. Milwaukee, WI: ASQC Quality.

Issler O, Haramati S, Paul ED, Maeno H, Navon I, Zwang R, Gil S, Mayberg HS, Dunlop BW, Menke A, Awatramani R, Binder EB, Deneris ES, Lowry CA, Chen A (2014) MicroRNA 135 is essential for chronic stress resiliency, antidepressant efficacy, and intact serotonergic activity. Neuron 83:344-360.

Jacobs BL, Azmitia EC (1992) Structure and function of the brain serotonin system. Physiol Rev 72:165-229.

Kawahara H, Yoshida M, Yokoo H, Nishi M, Tanaka M (1993) Psychological stress increases serotonin release in the rat amygdala and prefrontal cortex assessed by in vivo microdialysis. Neurosci Lett 162:81-84.

Kelly KJ, Donner NC, Hale MW, Lowry CA (2011) Swim stress activates serotonergic and nonserotonergic neurons in specific subdivisions of the rat dorsal raphe nucleus in a temperature-dependent manner. Neuroscience 197:251-268.

Kesby JP, Najera JA, Romoli B, Fang Y, Basova L, Birmingham A, Marcondes MCG, Dulcis D, Semenova S (2017) HIV-1 TAT protein enhances sensitization to methamphetamine by affecting dopaminergic function. Brain Behav Immun 65:210-221.

Kranz GS, Kasper S, Lanzenberger R (2010) Reward and the serotonergic system. Neuroscience 166:1023-1035.

Krishnan V,Han MH, Graham DL, Berton O, Renthal W, Russo SJ, Laplant Q, Graham A, Lutter M, Lagace DC, Ghose S, Reister R, Tannous P, Green TA, Neve RL, Chakravarty S, Kumar A, Eisch AJ, Self DW, Lee FS, et al. (2007) Molecular adaptations underlying susceptibility and resistance to social defeat in brain reward regions. Cell 131:391-404.

Lehmann ML, Herkenham M (2011) Environmental enrichment confers stress resiliency to social defeat through an infralimbic cortex-dependent neuroanatomical pathway. J Neurosci 31:6159-6173.

Li Y, Zhong W, Wang D, Feng Q, Liu Z, Zhou J, Jia C, Hu F, Zeng J, Guo Q, Fu L, Luo M (2016) Serotonin neurons in the dorsal raphe nucleus encode reward signals. Nat Commun 7:10503.

Lira A, Zhou M, Castanon N, Ansorge MS, Gordon JA, Francis JH, BradleyMoore M, Lira J, Underwood MD, Arango V, Kung HF, Hofer MA, Hen R, Gingrich JA (2003) Altered depression-related behaviors and functional changes in the dorsal raphe nucleus of serotonin transporterdeficient mice. Biol Psychiatry 54:960-971.

Liu Z, Zhou J, Li Y, Hu F, Lu Y, Ma M, Feng Q, Zhang JE, Wang D, Zeng J, Bao J, Kim JY, Chen ZF, El Mestikawy S, Luo M (2014) Dorsal raphe neurons signal reward through 5-HT and glutamate. Neuron 81:1360-1374.

Lopes DA, Lemes JA, Melo-Thomas L, Schor H, de Andrade JS, Machado CM, Horta-Júnior JA, Céspedes IC, Viana MB (2016) Unpredictable chronic mild stress exerts anxiogenic-like effects and activates neurons in the dorsal and caudal region and in the lateral wings of the dorsal raphe nucleus. Behav Brain Res 297:180-186.

López-Ibor JJ (1988) The involvement of serotonin in psychiatric disorders and behaviour. Br J Psychiatry Suppl 153:26-39.

Lowry CA, Rodda JE, Lightman SL, Ingram CD (2000) Corticotropinreleasing factor increases in vitro firing rates of serotonergic neurons in the rat dorsal raphe nucleus: evidence for activation of a topographically organized mesolimbocortical serotonergic system. J Neurosci 20:77287736 .

Lucki I (1998) The spectrum of behaviors influenced by serotonin. Biol Psychiatry 44:151-162.

Maier SF, Watkins LR (2005) Stressor controllability and learned helplessness: the roles of the dorsal raphe nucleus, serotonin, and corticotropinreleasing factor. Neurosci Biobehav Rev 29:829-841.

Martinez M, Calvo-Torrent A, Pico-Alfonso MA (1998a) Social defeat and subordination as models of social stress in laboratory rodents: a review. Aggress Behav 24:241-256.

Martinez M, Phillips PJ, Herbert J (1998b) Adaptation in patterns of c-fos expression in the brain associated with exposure to either single or repeated social stress in male rats. Eur J Neurosci 10:20-33. 
Martinez M, Calvo-Torrent A, Herbert J (2002) Mapping brain response to social stress in rodents with c-fos expression: a review. Stress 5:3-13.

Meng D, Li HQ, Deisseroth K, Leutgeb S, Spitzer NC (2018) Neuronal activity regulates neurotransmitter switching in the adult brain following light-induced stress. Proc Natl Acad Sci U S A 115:5064-5071.

Mokler DJ, Torres OI, Galler JR, Morgane PJ (2007) Stress-induced changes in extracellular dopamine and serotonin in the medial prefrontal cortex and dorsal hippocampus of prenatally malnourished rats. Brain Res 1148:226-233.

Müller CP, Homberg JR (2015) The role of serotonin in drug use and addiction. Behav Brain Res 277:146-192.

Murphy KL, Zhang X, Gainetdinov RR, Beaulieu JM, Caron MG (2008) A regulatory domain in the $\mathrm{N}$ terminus of tryptophan hydroxylase 2 controls enzyme expression. J Biol Chem 283:13216-13224.

Natarajan R, Forrester L, Chiaia NL, Yamamoto BK (2017) Chronic-stressinduced behavioral changes associated with subregion-selective serotonin cell death in the dorsal raphe. J Neurosci 37:6214-6223.

Negus SS, Miller LL (2014) Intracranial self-stimulation to evaluate abuse potential of drugs. Pharmacol Rev 66:869-917.

Nestler EJ, Carlezon WA Jr (2006) The mesolimbic dopamine reward circuit in depression. Biol Psychiatry 59:1151-1159.

Olds J, Milner P (1954) Positive reinforcement produced by electrical stimulation of septal area and other regions of rat brain. J Comp Physiol Psychol 47:419-427.

Osacka J, Szelle Cernackova A, Horvathova L, Majercikova Z, Pirnik Z, Kiss A (2018) Clozapine impact on c-fos expression in mild stress preconditioned male rats exposed to a novelty stressor. J Neurosci Res 96:1786-1797.

Paul ED, Hale MW, Lukkes JL, Valentine MJ, Sarchet DM, Lowry CA (2011) Repeated social defeat increases reactive emotional coping behavior and alters functional responses in serotonergic neurons in the rat dorsal raphe nucleus. Physiol Behav 104:272-282.

Paxinos G, Watson C (2014) The rat brain in stereotaxic coordinates, Ed 7. London: Elsevier Science.

Pelosi B, Migliarini S, Pacini G, Pratelli M, Pasqualetti M (2014) Generation of Pet $1_{210}$-cre transgenic mouse line reveals non-serotonergic expression domains of Pet1 both in CNS and periphery. PLoS One 9:e104318.

Pessia M, Jiang ZG, North RA, Johnson SW (1994) Actions of 5-hydroxytryptamine on ventral tegmental area neurons of the rat in vitro. Brain Res 654:324-330.

Peyron C, Petit JM, Rampon C, Jouvet M, Luppi PH (1997) Forebrain afferents to the rat dorsal raphe nucleus demonstrated by retrograde and anterograde tracing methods. Neuroscience 82:443-468.

Poeggel G, Nowicki L, Braun K (2003) Early social deprivation alters monoaminergic afferents in the orbital prefrontal cortex of octodon degus. Neuroscience 116:617-620.

Pollak Dorocic I, Fürth D, Xuan Y, Johansson Y, Pozzi L, Silberberg G, Carlén M, Meletis K (2014) A whole-brain atlas of inputs to serotonergic neurons of the dorsal and median raphe nuclei. Neuron 83:663-678.

Pomrenze MB, Millan EZ, Hopf FW, Keiflin R, Maiya R, Blasio A, Dadgar J, Kharazia V, De Guglielmo G, Crawford E, Janak PH, George O, Rice KC, Messing RO (2015) A transgenic rat for investigating the anatomy and function of corticotrophin releasing factor circuits. Front Neurosci 9:487.

Qi J, Zhang S, Wang HL, Wang H, de Jesus Aceves Buendia J, Hoffman AF, Lupica CR, Seal RP, Morales M (2014) A glutamatergic reward input from the dorsal raphe to ventral tegmental area dopamine neurons. Nat Commun 5:5390.

Ren J, Friedmann D, Xiong J, Liu CD, Ferguson BR, Weerakkody T, DeLoach KE, Ran C, Pun A, Sun Y, Weissbourd B, Neve RL, Huguenard J, Horowitz MA, Luo L (2018) Anatomically defined and functionally distinct dorsal raphe serotonin sub-systems. Cell 175:472-487.e20.

Riga D, Theijs JT, De Vries TJ, Smit AB, Spijker S (2015) Social defeatinduced anhedonia: effects on operant sucrose-seeking behavior. Front Behav Neurosci 9:195.

Roiser JP, Müller U, Clark L, Sahakian BJ (2007) The effects of acute tryptophan depletion and serotonin transporter polymorphism on emotional processing in memory and attention. Int J Neuropsychopharmacol 10:449-461.

Rolls ET (2000) The orbitofrontal cortex and reward. Cereb Cortex $10: 284-294$

Romoli B, Lozada AF, Sandoval IM, Manfredsson FP, Hnasko TS, Berg DK, Dulcis D (2019) Neonatal nicotine exposure primes midbrain neurons to a dopaminergic phenotype and increases adult drug consumption. Biol Psychiatry 86:344-355.

Russo SJ, Murrough JW, Han MH, Charney DS, Nestler EJ (2012) Neurobiology of resilience. Nat Neurosci 15:1475-1484.

Rygula R, Abumaria N, Flügge G, Fuchs E, Rüther E, Havemann-Reinecke U (2005) Anhedonia and motivational deficits in rats: impact of chronic social stress. Behav Brain Res 162:127-134.

Schindelin J, Arganda-Carreras I, Frise E, Kaynig V, Longair M, Pietzsch T, Preibisch S, Rueden C, Saalfeld S, Schmid B, Tinevez JY, White DJ, Hartenstein V, Eliceiri K, Tomancak P, Cardona A (2012) Fiji: an opensource platform for biological-image analysis. Nat Methods 9:676-682.

Seymour B, Daw ND, Roiser JP, Dayan P, Dolan R (2012) Serotonin selectively modulates reward value in human decision-making. J Neurosci 32:5833-5842.

Spencer WC, Deneris ES (2017) Regulatory mechanisms controlling maturation of serotonin neuron identity and function. Front Cell Neurosci 11:215.

Spitzer NC (2017) Neurotransmitter switching in the developing and adult brain. Annu Rev Neurosci 40:1-19.

Stanisavljević A, Perić I, Bernardi RE, Gass P, Filipović D (2019) Clozapine increased c-fos protein expression in several brain subregions of socially isolated rats. Brain Res Bull 152:35-44.

Steinbusch HWM (1981) Distribution of serotonin-immunoreactivity in the central nervous system of the rat-cell bodies and terminals. Neuroscience 6:557-618.

Swiergiel AH, Takahashi LK, Kalin NH (1993) Attenuation of stressinduced behavior by antagonism of corticotropin-releasing factor receptors in the central amygdala in the rat. Brain Res 623:229-234.

Treadway MT, Zald DH (2011) Reconsidering anhedonia in depression: lessons from translational neuroscience. Neurosci Biobehav Rev 35:537-555.

Underwood MD, Khaibulina AA, Ellis SP, Moran A, Rice PM, Mann JJ, Arango V (1999) Morphometry of the dorsal raphe nucleus serotonergic neurons in suicide victims. Biol Psychiatry 46:473-483.

van Zessen R, Phillips JL, Budygin EA, Stuber GD (2012) Activation of VTA GABA neurons disrupts reward consumption. Neuron 73:1184-1194.

Velázquez-Ulloa NA, Spitzer NC, Dulcis D (2011) Contexts for dopamine specification by calcium spike activity in the CNS. J Neurosci 31:78-88.

Vialou V, Robison AJ, Laplant QC, Covington HE 3rd, Dietz DM, Ohnishi YN, Mouzon E, Rush AJ 3rd, Watts EL, Wallace DL, Iñiguez SD, Ohnishi YH, Steiner MA, Warren BL, Krishnan V, Bolaños CA, Neve RL, Ghose S, Berton O, Tamminga CA, et al. (2010) $\Delta$ FosB in brain reward circuits mediates resilience to stress and antidepressant responses. Nat Neurosci 13:745-752.

Walther DJ, Peter JU, Bashammakh S, Hörtnagl H, Voits M, Fink H, Bader M (2003) Synthesis of serotonin by a second tryptophan hydroxylase isoform. Science 299:76.

Wang HL, Zhang S, Qi J, Wang H, Cachope R, Mejias-Aponte CA, Gomez JA, Mateo-Semidey GE, Beaudoin GMJ, Paladini CA, Cheer JF, Morales M (2019) Dorsal raphe dual serotonin-glutamate neurons drive reward by establishing excitatory synapses on VTA mesoaccumbens dopamine neurons. Cell Rep 26:1128-1142.e7.

Weissbourd B, Ren J, DeLoach KE, Guenthner CJ, Miyamichi K, Luo L (2014) Presynaptic partners of dorsal raphe serotonergic and GABAergic neurons. Neuron 83:645-662.

Wood SK, Zhang XY, Reyes BA, Lee CS, Van Bockstaele EJ, Valentino RJ (2013) Cellular adaptations of dorsal raphe serotonin coping in response to social stress. Biol Psychiatry 73:1087-1094.

Young JW, Cope ZA, Romoli B, Schrurs E, Aniek Joosen A, van Enkhuizen J, Sharp RF, Dulcis D (2018) Mice with reduced DAT levels recreate seasonal-induced switching between states in bipolar disorder. Neuropsychopharmacology 43:1721-1731.

Zhang J, Fan Y, Li Y, Zhu H, Wang L, Zhu MY (2012) Chronic social defeat up-regulates expression of the serotonin transporter in rat dorsal raphe nucleus and projection regions in a glucocorticoid-dependent manner. J Neurochem 123:1054-1068.

Zhang X, Beaulieu JM, Sotnikova TD, Gainetdinov RR, Caron MG (2004) Tryptophan hydroxylase-2 controls brain serotonin synthesis. Science 305:217.

Zhou QG, Zhu LJ, Chen C, Wu HY, Luo CX, Chang L, Zhu DY (2011) Hippocampal neuronal nitric oxide synthase mediates the stress-related depressive behaviors of glucocorticoids by downregulating glucocorticoid receptor. J Neurosci 31:7579-7590.

Zisook S, Paulus M, Shuchter SR, Judd LL (1997) The many faces of depression following spousal bereavement. J Affect Disord 45:85-95. 